\title{
TIPO, FUNCIÓN Y SOCIEDAD EVOLUCIÓN DEL ESPACIO CARCELARIO EN GALICIA
}

\author{
Por \\ JESÚS ÁNGEL SÁNCHEZ GARCÍA
}

\begin{abstract}
Este trabajo se centra en un tema como el de la cárcel que hasta la fecha apenas ha concitado la atención de los historiadores de la arquitectura en Galicia, en una situación de olvido compartida por otros tipos edificatorios cuya implantación, sin embargo, representará para nuestra tierra uno de los mejores indicadores del tránsito hacia la arquitectura y el urbanismo contemporáneos. Además, pese a ser una de las dotaciones públicas menos apreciadas debido a la negativa valoración social de su cometido, veremos como se conservan muestras de gran interés tanto por sus intrínsecos valores arquitectónicos como por el ciclo tipológico que posibilitan recorrer a lo largo de los siglos XVIII y XIX, cuando su presencia se generaliza y se convierten en hitos destacados dentro del entramado urbano. En lo que se refiere a su formalización éste será también uno de los tipos edificatorios que más debates genere durante la Edad Contemporánea, de una parte por su indispensable utilidad pública y de otra como resultado de las nuevas teorías desarrolladas desde la Ilustración sobre las características del cuerpo social y el papel de la arquitectura de cara a colaborar en su perfeccionamiento, aspecto del que igualmente nos ocuparemos al rastrear su incidencia en las cárceles construidas en Galicia.
\end{abstract}

"CUADERNOS DE ESTUDIOS GALLEGOS", Tomo XLVI, Fascículo 111, Santiago 1999. 


\section{ANTECEDENTES. DE LA EDAD MEDIA AL SIGLO XVIII: UNA FUNCIÓN A LA BÚSQUEDA DE UN EDIFICIO PROPIO}

Como punto de partida puede afirmarse que desde la Edad Media hasta el siglo XVIII Galicia compartió con el resto de España el mismo panorama penitenciario en el que se tendía a ver en la cárcel simplemente un lugar de encierro durante un corto espacio de tiempo, mientras el recluso esperaba el juicio y posterior cumplimiento de una pena que en la mayoría de los casos consistía en un castigo corporal, cuando no la propia muerte. Por esta consideración del lugar de reclusión como antesala del castigo, la cárcel no será todavía una arquitectura especializada, sino que se instalará en recintos construidos para otras finalidades como castillos, torres, murallas, casas consistoriales, palacios, conventos, obviando muchas veces requisitos a primera vista imprescindibles como el de estar dotadas de unas fábricas pétreas de cierta robustez para impedir las mismas fugas de los presos ${ }^{1}$. Esta concepción de edificio-depósito repercutirá en una organización interior resuelta de forma sumaria y despreocupada por lograr unos mínimos parámetros de habitabilidad: con calabozos comunes donde se hacinaban unos presos mezclados indistintamente, sin observar siquiera la norma de la separación por sexos, y todo en medio de una lacerante falta de condiciones en cuanto a aireación, salubridad o higiene, por tratarse en la mayoría de los casos de dependencias subterráneas.

$\mathrm{Al}$ margen de las mazmorras ubicadas en el interior de nuestras fortalezas, Galicia contó con ejemplos de todo el abanico de cárceles medievales que, desde tiempos de Alfonso X el Sabio y según Bonet Correa, se agruparían en cárceles reales, de villa, eclesiásticas y de la Inquisición, estas dos últimas fuera de la jurisdicción regia ${ }^{2}$. En cuanto a los recintos utilizados para cubrir esta función, entre los casos de aprovechamiento de edificaciones defensivas tenemos el ejemplo de Ourense, cuya cárcel clerical se instaló en la torre levantada por el obispo D. Diego Velasco a

\footnotetext{
${ }^{1}$ Por ello en aquellos tiempos la seguridad que no podía ofrecer el propio edificio se compensaba con recursos personales para inmovilizar al preso como eran las cadenas, argollas, grillos, cepos o esposas. GARCÍA BASALO, J.C. (1957a), 71 a 83.

${ }^{2}$ BONET CORREA, A. (1978), 139 a 144.
}

"CUADERNOS DE ESTUDIOS GALLEGOS", Tomo XLVI, Fascículo 111, Santiago 1999. 
principios del siglo XII, frente al palacio episcopal ${ }^{3}$, o el de Ribadeo con su fortaleza del XIV. En A Coruña la cárcel medieval, según recoge Estrada Gallardo, estaba fundada sobre un lienzo de la muralla en la zona del Parrote, hacia la puerta por donde se desembarcaban las mercancías que venían por mar, arruinándose en 1550 por el derrumbe de parte de aquella cerca $^{4}$. De forma similar en Lugo las cárceles Real y eclesiástica se encontraban en el antiguo castillo emplazado en la plaza o campo del mismo nombre, contiguo a la muralla, mientras que la cárcel de seglares se situaba al lado de la catedral ${ }^{5}$.

Con el Renacimiento y el Barroco aparecerán al igual que en el resto de España las primeras cárceles dotadas de un edificio propio, ya aspirando a ofrecer una imagen y condiciones cuando menos dignas, que progresivamente huirán de la lobreguez y anonimato anteriores ${ }^{6}$. Así, la cárcel como arquitectura intentará situarse tanto a la altura de otros nacientes edificios públicos como de la misma renovación del caserío, fenómenos que poco a poco contribuían a cambiar el aspecto de nuestras ciudades. Sin embargo, para las construidas en nuestra tierra ésto no dejó de ser en la mayoría de los casos un ideal inalcanzable puesto que veremos como todo lo más se configurarán en las principales poblaciones como grandes caserones de fuertes muros apenas horadados por los indispensables tragaluces, en los que tan solo esa rotundidad parietal y algún escudo o inscripción servirán de elementos diferenciadores con la arquitectura residencial.

En esta línea cabe valorar cárceles desaparecidas como la coruñesa de la calle Herrerías o las cárceles seglar y eclesiástica de Santiago, en especial estas últimas ya que eran dos pequeñas y anodinas edificaciones con patios, situadas junto a la muralla de la ciudad en la zona que hoy ocupa el Palacio de Rajoy, en la plaza del Obradoiro. Si bien todo parece apun-

\footnotetext{
${ }^{3}$ BANDE RODRÍGUEZ, E. y FERNÁNDEZ RODRÍGUEZ, L. (1993), 23.

${ }^{4}$ ESTRADA GALLARDO, F. (1970), 333 a 355.

${ }^{5}$ AMOR MEILÁN, M. (1930), Vol. VIII, 148.

${ }^{6}$ Para la provincia de Ourense Olga Gallego recoge la incidencia de un auto del Real Acuerdo del 17 de Marzo de 1603 por el que prácticamente se eliminaron los calabozos y mazmorras subterráneos de las fortalezas, haciéndose cárceles «donde suelen y acostumbran hacer audiencias públicas de ordinario, decentes y seguras». GALLEGO DOMÍNGUEZ, O. (1995).
} 
tar a que la cárcel eclesiástica ya existía desde finales de la Edad Media, en una torre defensiva junto a la puerta de las Huertas, lo cierto es que en el XVII se le añadiría la cárcel pública, sufriendo ambas en adelante constantes reedificaciones gracias a las cuales lograrían mantenerse en uso hasta las postrimerías del siglo XVIII ${ }^{7}$. En cuanto a la cárcel de villa de Pontevedra, fue construida a partir de 1595 adoptando la forma de un inmueble de dos plantas adosado a la torre bajo la que se encontraba la puerta del Puente del Burgo (Fig. 1); por lo tanto pese a su escasa entidad arquitectónica era bien visible en la principal entrada urbana ${ }^{8}$.

Otro ejemplo, ya del pleno barroco, es la cárcel de la Corona construida en Ourense en tiempos del obispo Muñoz de la Cueva, en 1719 (Fig. 2). Está situada frente a la huerta del Palacio Episcopal, aún aprovechando su planta baja para otro uso bien distinto como era el de pescadería. En su fachada principal incorpora una serie de elementos de la arquitectura culta como la ornamentada portada con el escudo del prelado, con el capelo de siete borlas, o las molduras de las ventanas y puertas adyacentes ${ }^{9}$. En cambio la cárcel del Concejo se alojaba desde el siglo XVI en el antiguo hospitalillo de la rúa das Chousas, hoy Libertad, donde persistió hasta que se construyó la provincial en 1837.

Sin embargo, en nuestra tierra lo más frecuente será que esta mejora en el aspecto de la cárcel fuera producto de su integración dentro de las nuevas tipologías de edificios públicos entonces en alza como las casas consistoriales o, sobre todo, los usados para la administración de justicia como las Audiencias. De hecho, gracias a la edilicia de otra institución, la Iglesia, se levantaría incluyendo la función de cárcel el desaparecido edificio de la Inquisición de Santiago, situado en la zona que ocupa el actual Hotel Compostela, en la plaza de Galicia. Para esta obra se conserva un proyecto previo, de la segunda mitad del XVII y que Bonet Correa atribuye a Diego de Romay, donde se plantea un inmueble de cierto empaque,

\footnotetext{
${ }^{7}$ Sobre su situación exacta y características ofrecen interesantes datos los estudios de ORTEGA ROMERO, M. S. (1981), 525 a 530; y PÉREZ RODRÍGUEZ, F. (1995), 239 a 272 .

${ }^{8}$ JUEGA PUIG, J (1985), 231 a 254; y JUEGA PUIG, J., PEÑA SANTOS, A. de la, SOTELO RESURRECCIÓN, E. (1995), 88 y 133 a 146. De sus avatares posteriores, por haber sido reconstruida en 1750 , nos ocuparemos más adelante.

${ }^{9}$ RISCO, V. (1930), Vol. XI, 279; y GALLEGO DOMÍNGUEZ, O. (1995).
} 


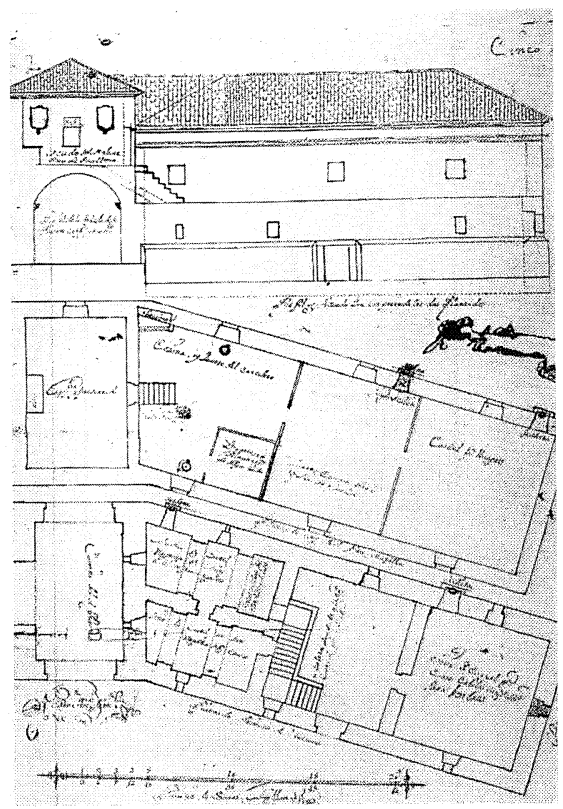

Fig. 1.- Pontevedra. Cárcel de Villa. Planos de 1750 para su reconstrucción. (Fuente: JUEGA PUIG, J. 1985).

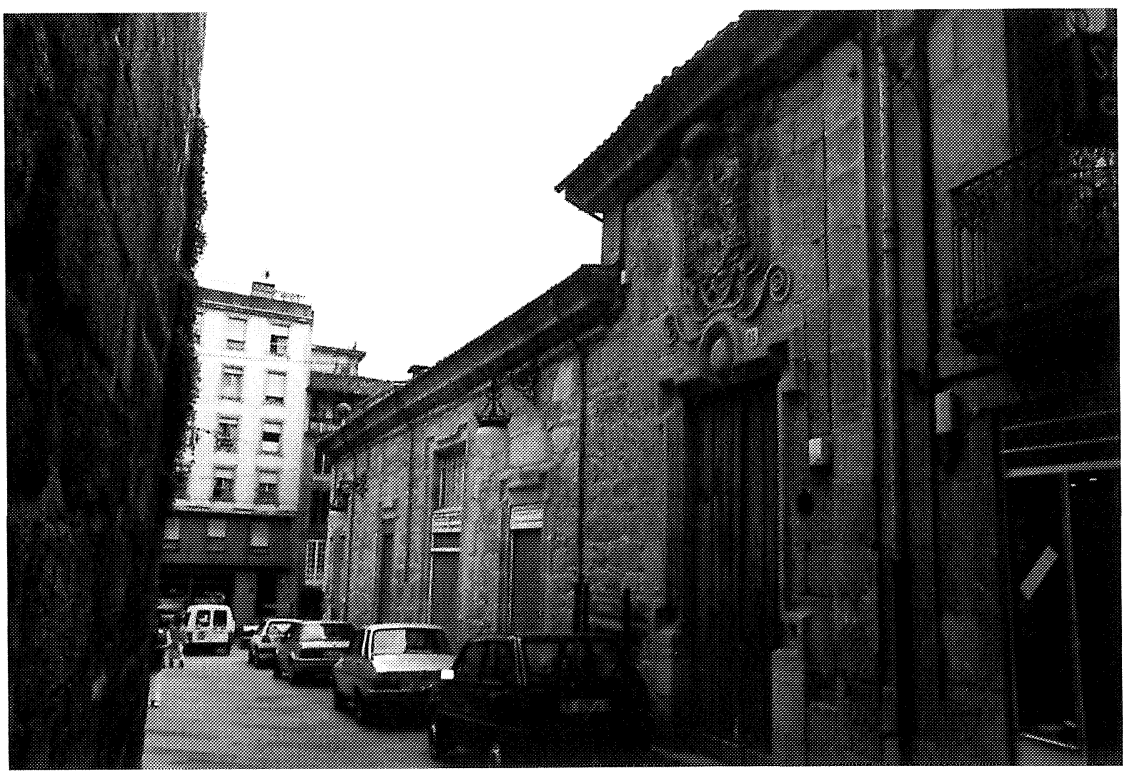

Fig. 2.- Ourense. Cárcel de la Corona, 1719. 
con una clasicista fachada organizada por grandes pilastras, que además de albergar el tribunal eclesiástico incluiría las usuales cárceles públicas, medianas y secretas ${ }^{10}$. La construcción definitiva, emplazada frente a la Porta da Mámoa tras desecharse la zona de San Martín Pinario, se atribuye a Fernando de Casas Novoa y estaba concluida en los años 30 del siglo $\mathrm{XVIII}^{11}$. El porte de palacio urbano logrado en su fachada principal gracias a los balcones o el cuerpo central flanqueado por dos grandes columnas sobre alto pedestal se imponía ante cualquier referencia a la función represiva también desempeñada ${ }^{12}$.

Estos primeros pasos hacia la dignificación del edificio carcelario mediante su inclusión en una construcción de nueva planta y dependiente de alguno de los poderes fácticos de la época tendrán continuidad en la segunda mitad del siglo XVIII, durante la gestación del neoclasicismo, como se aprecia en la inserción dentro del Seminario de Confesores y Ayuntamiento de Santiago costeado por el arzobispo Rajoy de unas plantas inferiores dedicadas a cárceles secular y eclesiástica ${ }^{13}$. Aprovechando el desnivel del terreno existente los sótanos donde se encuentran los calabozos rodean el patio interior y se orientan hacia la fachada posterior para mostrar, en contraste con el elegante y afrancesado frente hacia la plaza del Obradoiro, unos muros con fábrica de gruesa mampostería y la rítmi-

${ }^{10}$ BONET CORREA, A. (1984), 439 a 442.

${ }^{11} \mathrm{El}$ anterior proyecto de Fernando de Casas del año 1726, destinado a ampliar la primitiva sede instalada desde los años 60 del siglo XVI en el Palacio de los Condes de Monterrey, hacia la Puerta de la Peña en las inmediaciones de San Martín, fue identificado por Socorro Ortega, puesto que anteriormente Bonet Correa lo había atribuido a Diego de Romay: ORTEGA ROMERO, M.S. (1987), 653 a 668.

${ }^{12}$ Pese a la calidad de su fábrica, enteramente en sillería, fue demolido en el año 1913. COSTA BUJÁN, P. y MORENAS AYDILLO, J. (1989), 94 y 95; y GARCÍA IGLESIAS, J.M. (1995), 38 y 39.

${ }^{13}$ Para este edificio había dado unos primeros planos en 1764 Lucas Ferro Caaveiro, si bien sólo con dedicación a Consistorio y cárceles seglar y eclesiástica, situadas en dos cuerpos a los lados del principal. Luego, en 1766 elaboraría una nueva propuesta el maestro Andrés García de Quiñones, con idéntica distribución espacial pero ahora las cárceles flanqueando al Seminario central. A partir de aquí y por las reclamaciones municipales ya se incluiría el tercer uso como Consistorio en un segundo proyecto de García de Quiñones y en el definitivo de Carlos Lemaur (1767), relegando las cárceles a los sótanos. Véanse al respecto los trabajos de ORTEGA ROMERO, M. S. (1966), 81 a 101 y (1983), 327 a 330; y VIGO TRASANCOS, A. (1992), 103 a 133.

"CUADERNOS DE ESTUdIOS GALLEGOS", Tomo XLVI, Fascículo 111, Santiago 1999. 
ca serie de ventanas enrejadas. En el interior toda la nobleza de las plantas principales cedía ante la lobreguez de unos calabozos que a mediados del siglo XIX serían duramente criticados en el Diccionario de $\mathrm{Madoz}^{14}$.

De todas formas, al margen de los casos reseñados lo más usual continuó siendo el aprovechamiento de edificios de varia finalidad, principalmente defensivos, como por ejemplo la fortaleza de San Antón a la entrada del puerto de A Coruña. En ella ya desde su construcción a finales del XVI se habilitaron «aposentos» que servían tanto de prisión militar como de acuartelamiento ${ }^{15}$. En este sentido hay que apuntar que estos recursos no diferían en modo alguno de las prácticas observadas en el resto de la Península, por lo que la condición de región periférica de Galicia la situaba al mismo nivel que otras provincias en cuanto a la inadecuación de sus recintos carcelarios. Tan solo las principales ciudades de la época, como Madrid y Sevilla, podían ofrecer prisiones de gran envergadura y construidas exclusivamente para esa finalidad como eran la renacentista cárcel de San Fernando de Sevilla o la barroca de Corte en Madrid; esta última era sin duda alguna la principal cárcel de España, construida en 1634 por Juan Gómez de Mora y Juan Bautista Crescenzi ${ }^{16}$.

Sin embargo, con independencia de la mayor o menor prestancia arquitectónica externa adquirida en estos siglos, en lo referente a su organización y características interiores la solución del calabozo común donde los presos eran reducidos a un estado infrahumano seguirá como nota dominante en todos los casos citados. Será necesario que se produzca una reflexión en profundidad sobre la eficacia y medios del castigo, enten-

\footnotetext{
${ }^{14}$ «Cárceles públicas y eclesiásticas, que abren sus fuertes rejas a espaldas del edificio: estas cárceles, de las cuales la primera tiene una fuente en el interior, son de bóveda y tan seguras como malas; sus calabozos, especialmente los de la civil, son contrarios a la humanidad». MADOZ, P. (1847), Tomo IV, 1191.

${ }^{15}$ Además, tras las reformas del XVIII este castillo consolidaría este uso al servir en este siglo y en el XIX como prisión militar y civil. SORALUCE BLOND, J. R. (1985), 103 a 110.

${ }^{16}$ Ambas se caracterizarán ya por ser unos inmuebles con un patio o patios interiores para el paseo y aireamiento de los presos, mejora luego consolidada y hecha norma constructiva en el XVIII. Además, la cárcel de Corte de Madrid por estar reservada a nobles y sujetos distinguidos se dotará de un porte palaciego con una elegante fachada principal flanqueada por dos torres, hoy sede del ministerio de Asuntos Exteriores. BONET CORREA, A. (1978), 139 a 144; FRAILE, P. (1989), 113 a 124.
}

"CUADERNOS DE ESTUDIOS GALLEGOS", Tomo XLVI, Fascículo 111, Santiago 1999. 
diendo la cárcel no ya como recinto de custodia sino como lugar de redención de la pena, para que tenga lugar una incidencia decisiva en la arquitectura penitenciaria ${ }^{17}$.

\section{LA SEGUNDA MITAD DEL SIGLO XVIII: LA IMPLANTA- CIÓN DE UN TIPO}

Llegamos así al siglo XVIII, período en el que bajo las Luces de la Ilustración una serie de destacados pensadores reaccionarán en toda Europa contra la forma de entender y aplicar el castigo a los delincuentes, buscando cambiar una situación en la que la desproporción entre delito y condena, con una excesiva aplicación de la pena de muerte o los castigos corporales habían demostrado ser medios insuficientes para contener la criminalidad, desbordando la misma capacidad punitiva de la justicia. Montesquieu y Rousseau en primer lugar reflexionarán sobre el origen del derecho a castigar fundándolo en una especie de pacto nuclear de la sociedad civil, por lo que para llegar a un estado de armonía y disciplina todo los ciudadanos debían sentir que las leyes eran objetivas y proporcionadas al delito cometido, eliminando los suplicios y castigos corporales por suponer una crueldad innecesaria e improductiva en favor de fórmulas de ejercicio del poder impersonales pero omnipresentes e inexorables. Desde estos presupuestos básicos, a partir de los años 60 se

\footnotetext{
${ }^{17}$ No por ello se puede negar la aparición desde el Renacimiento de precedentes en cuanto al replanteamiento del castigo y de la cárcel en base a la privación de libertad, o de la preocupación por mejorar sus condiciones materiales. Así, ya Filarete en su tratado de mediados del XV prefería el encarcelamiento de por vida antes que la pena de muerte, e incluía una propuesta de prisión con separación de los presos de acuerdo con el crimen cometido, mejora de la higiene en aireación, y disposición de celdas individuales para los peores delincuentes. Otro tanto hará Alberti al recomendar una distribución donde tuvieran cabida un patio o una capilla, tal y como analiza J. E. García Melero en relación a su conocimiento en la Academia de San Fernando. En España en esta misma línea se encuentra la obra del abogado de presos Tomás Cerdán de Tallada, Visita de la Cárcel y de los presos... (1574), también propugnando la separación según el crimen y condición, o defendiendo la necesidad de un lugar para disfrutar del sol y el aire, una capilla... PEVSNER, N. (1979), 189 a 202; GARCÍA MELERO, J. E. (1995); y GARCÍA BASALO, J.C. (1957a), 71 a 83.
}

"CUADERNOS DE ESTUDIOS GALLEGOS", Tomo XLVI, Fascículo 111, Santiago 1999. 
sistematizarán las nuevas teorías en materia penal con la trascendental obra del italiano Cesare Beccaria, De los delitos y las penas (1764), donde establecerá que el castigo debía servir tanto para disuadir de cometer crímenes como para regenerar al que ya los hubiera cometido, fundamentándose antes que en su intensidad en su duración a través de la prolongada privación de libertad. El encierro durante extensos períodos de tiempo será, pues, la idea base que acabe circulando por toda Europa, introduciendo esta noción más humanitaria en las reformas de los códigos penales de la época, aunque todavía habrán de pasar años hasta que también encuentre eco y aplicación en la reorganización de unas cárceles que por sus condiciones eran inútiles para llevar a la práctica esta forma de sometimiento $^{18}$.

En Galicia esos mismos años centrales y finales del siglo XVIII traen consigo la construcción de las primeras cárceles planteadas exclusivamente para esa función, pero ahora ya con un sentido representativo y una imagen arquitectónica a la altura de las mejores realizaciones edilicias, culminando así la evolución hacia su dignificación urbana que habíamos visto arrancar del Renacimiento y el Barroco. Por ello en esta centuria dieciochesca se introducirá en nuestra tierra una nueva concepción del edificio penal al proyectarse por iniciativa regia en Coruña o Ferrol cárceles de nueva planta, especializadas y organizadas interiormente para hacer frente a las exigencias de un encierro prolongado en el tiempo. Estas dos cárceles reales se revestirán además de una imagen seria, clasicista en su gramática estilística, pero combinada a la vez con una apariencia robusta y con el suficiente impacto visual como para hacer efectiva por parte del poder la transmisión del nuevo mensaje de sumisión que debían asimilar los ciudadanos para convertirse en obedientes cumplidores de las leyes. Sin embargo, pese a estos cambios todavía nos encontramos con la continuidad de la solución del confinamiento común

\footnotetext{
${ }^{18}$ En España estas reflexiones serán recogidas y desarrolladas con ciertos matices por Manuel de Lardizábal en su obra Discurso sobre las penas (1782): entendiendo el castigo como un mecanismo tendente a mantener el orden establecido, con leyes proporcionadas y objetivas, o un encierro en las cárceles donde también se incluyera algún tipo de trabajo para los presos, pero todavía abogando por la aplicación en ciertos casos de las penas corporales. La mejor síntesis de todos estos planteamientos y su incidencia en la arquitectura carcelaria puede encontrarse en FRAILE, P. (1989), 13 a 38.
} 
heredada de los siglos anteriores, solo que filtrada y dulcificada a través de las exigencias de racionalidad e higiene derivadas del pensamiento Ilustrado. Por estas ideas los grandes calabozos, ahora llamados «cuadras», se acompañarán de otras dependencias como servicios comunes, habitaciones del carcelero, salas para celebrar juicios, o una capilla. Como fórmula de organización del espacio se situarán en torno a un patio interior de forma cuadrada o trapezoidal que asegurara unas mínimas condiciones de aireación y salubridad para los condenados, por lo que se asentará una solución tipológica que ya contaba con precedentes ilustres como las reseñadas cárceles de Sevilla y Madrid, o la romana prisión de San Michele diseñada por Carlo Fontana (1703-1704).

La Cárcel Real de A Coruña se levantó entre 1753 y 1760 con planos del ingeniero militar Miguel Marín, corregidos finalmente por Antonio Gaver en 1758. Estaba situada en la Ciudad Vieja, a espaldas del Palacio también dieciochesco que albergaba al Capitán General y a la Audiencia del Reino, máxima institución de justicia con la que se comunicaba a través de un paso elevado sobre la calle (Fig. 3). Su planta irregular, dictada en la parte posterior por la adaptación a la ribera marítima, dejaba en

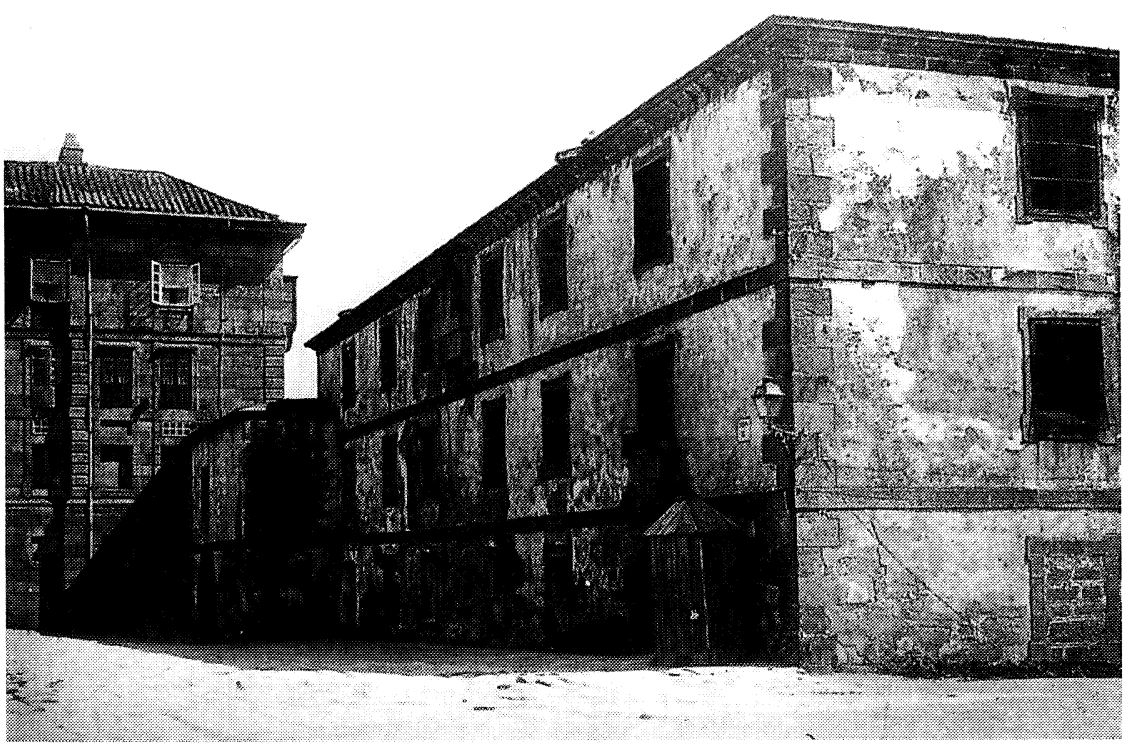

Fig. 3.- A Coruña. Antigua Cárcel Real en el Parrote. 1753-1760.

"CUADERNOS DE ESTUDIOS GALLEGOS", Tomo XLVI, Fascículo 111, Santiago 1999. 
el interior espacio para un patio trapezoidal al que se abrían en las dos primeras plantas los calabozos masculinos y una capilla, situándose encima las habitaciones del alcaide y celdas de mujeres. El gran escudo real de su fachada principal era el único recurso enfatizador de un edificio que, por lo demás, se resolvía externamente sin grandes pretensiones, con un reparto simétrico de vanos recercados en sillería, entre pisos separados por dos líneas de imposta, y una colocación también simétrica de dos puertas de entrada hacia los extremos, una de ellas sólo de adorno ${ }^{19}$.

En cuanto a Ferrol, entre 1765 y 1770 como parte integrante de las obras del Arsenal y siguiendo el plan definitivo de Sánchez Bort se había construido dentro del recinto naval un presidio para los condenados que en gran número se ocupaban de las tareas más penosas, como el achique de los diques. Estaba situado entre la tapia del Arsenal y el muro de cierre posterior del edificio de la Teneduría, y se configuraba como un largo rectángulo con dos pequeños patios interiores, con un frente de dos pisos muy sobrio en sus ventanas, portada almohadillada y bandas de piedra ${ }^{20}$. Junto con las cárceles también existentes en los arsenales de Cartagena y La Carraca, y los presidios de Ceuta y Orán, integraría la red de penales españoles reservados para los delitos más graves.

Más interesante es, sin embargo, la mencionada cárcel pública de Ferrol, ciertamente una obra de gran calidad en su diseño, máxime en relación a los ejemplos examinados hasta ahora. Además presenta la ventaja de conservarse en la actualidad, si bien muy reformada en su aspecto por el añadido de dos plantas sobre el inmueble original. Un primer proyecto de Dionisio Sánchez de Aguilera de 1786, del que se han perdido los planos, preveía construir un vasto edificio para consistorio y cárcel, junto con las sedes de la Audiencia, Peso Real y Casa del Corregidor, cerrando el sector norte de la plaza de los Dolores; le seguiría en 1791 otro debido al arquitecto benedictino Fray Plácido Caamiña, con los mismos usos y emplazamiento, a través de cuyas trazas publicadas por Vigo Trasancos

\footnotetext{
${ }^{19}$ Para más detalles sobre un edificio que fue demolido en 1928 véanse GARCÍAALCAÑIZ YUSTE, J. (1989), 61 a 69; y VIGO TRASANCOS, A. (1995a), 95 a 97.

${ }^{20}$ Como señala Vigo Trasancos tanto su encerrada ubicación como su rusticidad estaban en función de su dedicación carcelaria. VIGO TRASANCOS, A. (1984), 100 a 103.
}

"CUADERNOS DE ESTUDIOS GALLEGOS", Tomo XLVI, Fascículo 111, Santiago 1999. 
puede comprobarse el reparto de los calabozos y «cuadras», separando a hombres y mujeres, en torno al alargado patio interior centrado por la capilla $^{21}$. Su presupuesto demasiado costoso acabó por decidir a las autoridades de Marina a encargar un último proyecto, el definitivo de 1791 del ingeniero de marina D. José López Llanos, también para la plaza de los Dolores pero ya sólo destinado a cárceles y juzgados. Este sin duda será su mayor valor puesto que arquitectónicamente es un edificio de menor envergadura con respecto a los proyectos anteriores, que incluso en principio sólo preveía tener una altura, luego afortunadamente ampliada en otra planta.

Tras comenzarse las obras en la ubicación prevista, en 1793 se optaría por el traslado a unos terrenos frente a la Nueva Población o Barrio de la Magdalena, en la fachada urbana hacia el Arsenal, siguiendo la línea marcada por la iglesia de San Julián, lo que posibilitó la construcción de un inmueble exento, de planta rectangular, con pequeño patio central al que se abren otra vez los distintos calabozos y dependencias como la sala de Justicia, capilla, o la casa del carcelero (Fig. 4). A la altura de 1801 estaba concluido, aunque dada la amplitud de sus dependencias albergaría durante algunos años las propias oficinas del Ayuntamiento. Madoz en su Diccionario no ahorra elogios para el inmueble definiéndolo como:

«... (un) edificio digno de atención por su solidez, simetría y hermosa vista que presenta frente a la plaza de la Constitución. La comodidad y buen orden de sus calabozos y estancias, y lo espacioso del sitio que ocupa, hace menos sensible la suerte de los arrestados» ${ }^{22}$.

Exteriormente frente a la cárcel de A Coruña la mayor calidad constructiva reflejada en la sillería del basamento, esquinales, recercado de vanos y sus guardapolvos superiores encuentra también correspondencia con una portada de ingreso enmarcada por pilastras y rematada por un curvo frontón partido. Según recoge Alfredo Vigo como elementos significantes de la función del edificio estaba previsto que la portada contase con un escudo de armas y una figura alegórica de la Justicia, final-

\footnotetext{
${ }^{21}$ VIGO TRASANCOS, A. (1995b), 273 a 312.

${ }^{22}$ MADOZ, P. (1847), Tomo VIII, 538.
} 


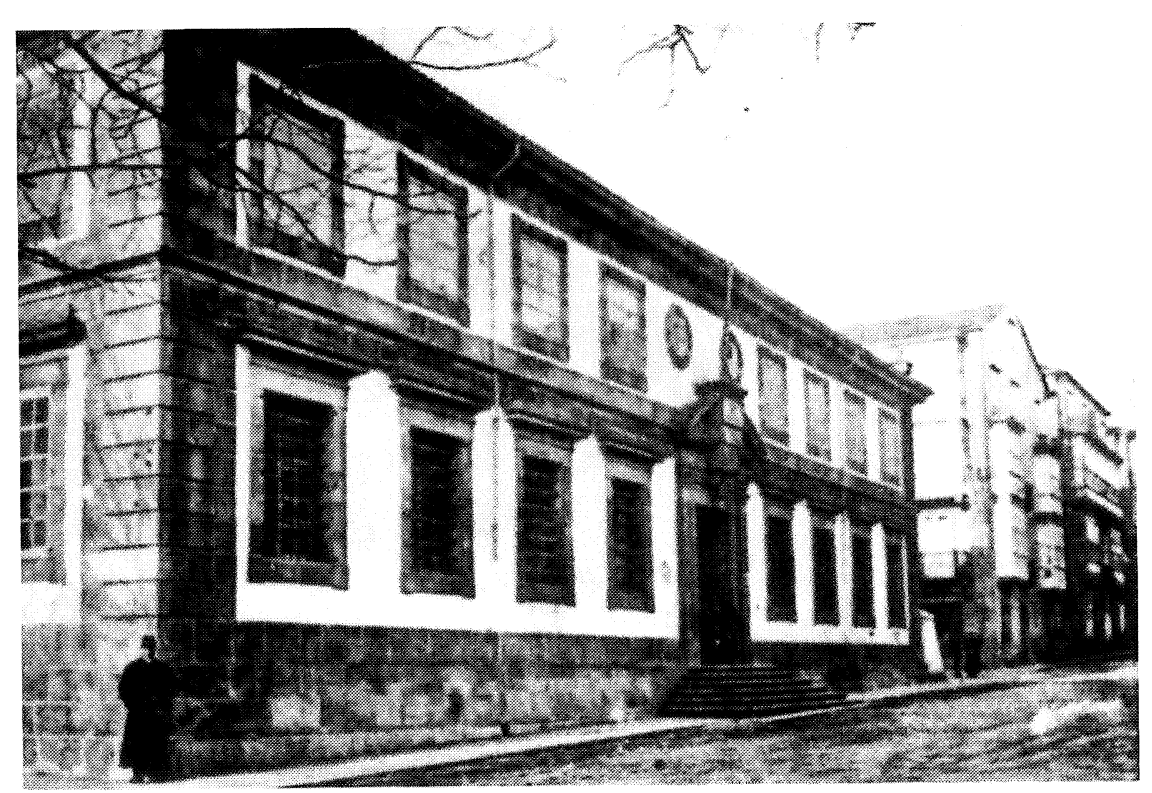

Fig. 4.- Ferrol. Antigua Cárcel Pública. 1791-1801. (Colección Guillermo Escrigas).

mente no realizadas ${ }^{23}$. En nuestro siglo albergaría un Instituto y posteriormente se convertiría en la sede del Gobierno Militar, reformándose la distribución interior a la vez que se añadían dos pisos más y se alteraban los vanos de la planta principal, donde se trasladó el frontón de la portada.

De características reseñables era también la desaparecida cárcel eclesiástica y civil de Mondoñedo, construida en los años 50 de la centuria por el Obispo Sarmiento y Sotomayor, a un lado del Hospital de San Pablo, en el Campo de los Remedios. Al margen del tipo de construcción con patio interior encarnada en las anteriores estaba la cárcel pública o de Armañá levantada en Lugo por el prelado de este nombre en 1776, y que Madoz definía como «un establecimiento de los mejores de su clase en toda Galicia». Situada en el solar que hoy ocupa el edificio del Gobierno Civil, cerca del convento de San Francisco, se trataba de un inmueble de una planta pero todo de cantería, con grandes salas abovedadas, y trabaja-

${ }^{23}$ VIGO TRASANCOS, A. (1984), 255 a 256. 
do escudo al exterior. En 1844 se le añadiría un segundo piso, continuando en su uso como cárcel hasta finales del XIX, cuando se inauguró la nueva ${ }^{24}$.

Siguiendo con la dinámica del resto del país, también en estos años en Galicia se utilizarán para la reclusión de quienes cometieran delitos de escasa y mediana gravedad las cárceles ya existentes, donde antes sólo se retenía a los procesados, pero siempre persistiendo en aquellas inadecuadas condiciones ya descritas. Así, en Pontevedra entre 1750 y 1753 se reedificó la cárcel del Puente del Burgo, destruida en el ataque inglés de 1719 , pero manteniendo unas dimensiones y distribución muy similares a la preexistente. A través de un plano conservado podemos saber que en el piso bajo se dispuso una sala judicial, en el primero los calabozos de hombres, con unos registros superiores abiertos hacia la capilla superior, y en el segundo la cárcel de mujeres con el cuarto del carcelero y una escalera de paso hacia la mencionada capilla, situada en el piso alto de la torre anexa ${ }^{25}$.

Más muestras de la continuidad en el aprovechamiento de edificios de otros usos se encuentran en localidades como Betanzos o Ribadeo. En Betanzos en el año 1776 se recurrirá a instalar la cárcel de la villa en una vieja casa de dos pisos y cuatro piezas interiores, medieval caserón de Fernán Pérez de Andrade, situado en la calle del Castro, inmueble que conservará esa dedicación hasta principios de nuestro siglo ${ }^{26}$. En Ribadeo el local elegido fue la antigua «Casa-Fábrica» de tejidos: construcción dieciochesca inaugurada en 1775 en la calle de San Roque y camino a Viveiro, pero que años después sería alquilada como almacenes y alojaría el Real Alfolí, la escuela o la propia cárcel que nos ocupa ${ }^{27}$.

\footnotetext{
${ }^{24}$ Más datos sobre esta cárcel de Armañá en MADOZ, P. (1847), Tomo IV, 766; AMOR MEILÁN, M. (1930), Vol. VIII, 145; y ABEL VILELA, A. (1984), 54 a 56.

${ }^{25}$ Ver nota 8. Estuvo en uso hasta que a principios del siglo XIX comenzó a remodelarse la zona del puente y su arranque, siendo derribada para construir un malecón y un tinglado para la venta de pescado.

${ }^{26}$ A.M.B. C-536. Obras Públicas. Edificios (1838-1868). También CARRE ALDAO, E. (1930), Vol. V, 796. De forma similar en Santiago se aprovechó parte del inmueble gótico situado en Casas Reales, desaparecido antes de acabar la centuria al edificarse la neoclásica Capilla de las Animas.

${ }^{27}$ LANZA ÁLVAREZ, F. (1973), 231 a 242 y 273 a 276.
}

"CUADERNOS DE ESTUDIOS GALLEGOS", Tomo XLVI, Fascículo 111, Santiago 1999. 
Por último, otra novedad de la centuria residirá en la aparición de «casas» o «establecimientos de corrección» donde se encerraba a vagos, mendigos o prostitutas para intentar convertirlos en personas útiles por medio de la realización de algunos trabajos comunitarios. De estas construcciones conocemos la existencia de una «casa Galera» para mujeres en A Coruña: localizada en la calle del mismo nombre en un caserón residencial con un notable escudo de armas que pertenecía a la familia Freyre de Andrade ${ }^{28}$.

\section{EL SIGLO XIX: PERSISTENCIAS Y RENOVACIÓN}

El panorama de las cárceles gallegas en el siglo XVIII pervivirá y se traspasará a la centuria decimonónica aún desaparecido el Antiguo Régimen, tras la muerte de Fernando VII, ya que para las cárceles construidas en la primera mitad del siglo XIX se seguirán adoptando tanto las soluciones más precarias como los modelos arquitectónicos de nueva planta dieciochescos. Al respecto hay que matizar que ésto no será algo exclusivo de Galicia sino que obedecerá al atraso general de un país y su marco legislativo en relación a las exigencias de la disposición de galerías radiales o la solución de confinamiento celular que se imponían en Europa ya desde fines del siglo XVIII. Frente a esos innegables avances hacia la configuración de la cárcel como edificio-máquina para corregir, la Ordenanza General de Presidios del Reino de 1834, vigente durante casi todo el ochocientos en España, únicamente aportaba la preocupación por clasificar a los condenados en tres categorías de encierros: los Depósitos correccionales para condenados a dos años, los Presidios Peninsulares para los de dos a ocho años, y los Presidios de Africa para los de más de ocho años ${ }^{29}$. Por lo demás, a nivel arquitectónico esta normativa seguía recurriendo al confinamiento común, con unos dormitorios herederos de las «cuadras» dieciochescas, y para los que sólo se recomendaba en aras de la misma preocupación higiénica que fueran largos, espaciosos, abovedados y con ventanas altas para introducir luz y ventilación.

${ }^{28}$ Allí estuvo instalada hasta que a finales del XIX las presas fueron llevadas a la cárcel del Parrote. NAYA PÉREZ, J. (1970), 125 a 126.

${ }^{29}$ FRAILE, P. (1989), 156 y 157.

"CUADERNOS DE ESTUDIOS GALLEGOS", Tomo XLVI, Fascículo 111, Santiago 1999. 
Este contexto legal, al que se unirá a la perenne carencia de recursos de nuestras autoridades municipales, provocará que el aprovechamiento de edificios preexistentes fuera la tónica dominante para habilitar cárceles tanto en las poblaciones mayores como en las menores. Por ejemplo en Santiago de Compostela en 1826 el Ayuntamiento y el Capitán General proyectaron la instalación de la Real Audiencia, Capitanía General, Cárceles y otras oficinas públicas a trasladar desde A Coruña en el edificio del Colegio de San Clemente ${ }^{30}$. Entre otros casos conocidos está el de la villa de Pontedeume, donde desde principios del siglo XIX se utilizará como cárcel el medieval Torreón de los Andrade ${ }^{31}$, a todas luces muy alejado de las condiciones exigibles a un recinto moderno.

Estas soluciones aún se generalizarán más a partir de la Desarmortización, cuando numerosos conventos de todo el país sean utilizados para instalar en su interior, otra vez muy inadecuadamente, las siempre necesarias cárceles. Así, en la propia capital de A Coruña el ex-convento de San Francisco se habilitará en principio provisionalmente como Presidio Provincial, mientras no se construía uno de nueva planta, aunque luego la incapacidad para abordar tal obra acabaría prolongando su uso, hasta que en 1879 por su pésimo estado un derrumbe en la zona del dormitorio ocasionaría varios muertos y el traslado de la cárcel al penal de Vallado$\operatorname{lid}^{32}$. La dinámica fue idéntica en Viveiro, utilizando desde 1842 el exconvento de San Francisco ${ }^{33}$, también sede del Ayuntamiento y Juzgados, o en villas menores como la de Ortigueira, que aprovecharía las dependencias del ex-convento de dominicos para alojar los principales servicios municipales: casa consistorial, escuela pública, cuartel de la milicia nacional y cárcel de partido ${ }^{34}$.

No faltarán ahora tampoco ejemplos de cárceles construidas de nueva planta, las más importantes las provinciales de Ourense y Pontevedra,

\footnotetext{
${ }^{30}$ Para ello encargaron planos al arquitecto académico Melchor de Prado y Mariño, al maestro de obras Fray Juan Conde y al ingeniero Felipe Gianzo, quienes presentaron sus diseños ante la Academia de San Fernando, que optó por los del primero. A.R.A.B.A.S.F. Actas Sección de Arquitectura. Libro 1824 a 1831. Junta del 23 de Mayo de 1826 , fols. 55 y 56 .

${ }^{31}$ CAINZOS CORBEIRA, A. (1995), 63 a 74.

${ }^{32}$ BARRAL RIVADULLA, D. (1995), 239 a 250.

${ }^{33}$ DONAPETRY (1953), 128.

${ }^{34}$ MADOZ, P. (1847), Tomo V, 940.
}

"CUADERNOS DE ESTUDIOS GALLEGOS", Tomo XLVI, Fascículo 111, Santiago 1999. 
pero para las cuales, como ya hemos adelantado, se mantendrá el modelo dieciochesco de construcción cuadrangular centrada por un patio. La cárcel de Ourense fue objeto ya en las postrimerías del XVIII de diferentes proyectos, como los de López Freire y Miguel Ferro Caaveiro del año 1787, este último desestimado por su alto coste de $396.000 \mathrm{rs}^{35}$; con ello tuvo que esperar hasta las primeras décadas del XIX para verse concretada, ahora con diseños debidos al arquitecto académico Alejo Andrade Yáñez ${ }^{36}$. Con estos nuevos planos las obras se iniciaron durante el Trienio Liberal en la zona del Outeiro, entre el río Barbaña y las Burgas, por donde luego discurrirá la carretera de Benavente a Vigo: vía que dará lu-gar a la actual calle del Progreso, eje principal del crecimiento urbano en el siglo XIX. Los trabajos conocieron diversas interrupciories por falta de fondos, prolongándose hasta que todavía en 1830 la Academia de San Fernando aprobaría los planos para su conclusión definitiva con una nueva propuesta de fachada que suprimía el segundo cuerpo proyectado originalmente por no ser necesario ni existir caudales suficientes para abordar$1 \mathrm{l}^{37}$. Tras la concesión en 1832 de nuevos arbitrios, y en 1835 de un

${ }^{35}$ En 1789 la ciudad de Ourense propondría costear la obra con un arbitrio sobre el vino y aguardiente, petición que sería denegada por el Intendente del Reino al recomendar que se formara otro proyecto a ubicar en el Campo del Outeiro y sin pasar de 150200.000 reales. Realizado por el arquitecto Francisco Martínez Vidal y aprobado por la Academia desechando el anterior, en 1799 aún se intentaba relanzarlo sin éxito, por lo que se mantuvo en uso la Cárcel de la Corona tras someterla a distintas reformas, como la de sus subterráneos en 1817. A.H.P.O. Libros de Actas Municipales, año 1789. Folios 103, 118 y 119. 19 de Noviembre y 4 de Diciembre. Sobre este mismo asunto incluye amplias referencias extraídas de la documentacion académica GARCÍA MELERO, J.E. (1995).

${ }^{36}$ Este personaje, que contaba a la vez con los estudios de ingeniero, desarrollará su actividad en distintas ciudades gallegas, ocupándose de obras públicas en Ourense, en Lugo, donde se lo designaba como «Ayudante facultativo de los Caminos transbersales del Norte de Galicia», Santiago y finalmente Coruña, donde realizaría su obra más conocida: la Capilla del Cementerio terminada en 1834. Posteriormente regresaría a Ourense para inspeccionar la terminación de su cárcel y diseñar el Teatro Principal costeado por D. Santiago Sáez Martínez. A la vez en 1838 elaboró planos para la Junta Suprema de Sanidad del Reino con destino al lazareto a construir en Vigo. A partir de aquí desaparecen las noticias, siendo muy probable que falleciera en 1844 , no sin dejar antes un proyecto de altar para la Capilla Mayor de la Catedral de Ourense y otro para la cárcel de Ribadavia. A.R.A.B.A.S.F.

${ }^{37}$ Este segundo cuerpo hacia la fachada principal se terminaría posteriormente. A.H.P.O. Libros de Actas Municipales, años 1830, folios 5 y 27, y 1831, folio 37. A.R.A.B.A.S.F. Actas Sección de Arquitectura. Libro 1824 a 1831. Junta del 16 de Agosto de 1831, fol. 213.

"CUADERNOS DE ESTUDIOS GALLEGOS", Tomo XLVI, Fascículo 111, Santiago 1999. 
repartimiento entre todos los pueblos de la provincia, finalmente en Noviembre de 1836 pudo quedar acabada en lo fundamental ${ }^{38}$. Poco después de su inauguración Madoz ya la recogería en su Diccionario afirmando que:

«No hay más que una cárcel, cuyo edificio es nuevo, cuadrado, de dos pisos, y un claustro por donde pasean los presos en ciertas horas; arriba hay una galería descubierta, y falta que concluir el cuerpo superior destinado para la guardia. Fue costeado por reparto hecho a la provincia» ${ }^{39}$.

Tanto a la vista de la ubicación de esta Cárcel Provincial en la que será calle principal de la ciudad como por sus dimensiones y calidad constructiva, al emplear únicamente sillería en su fábrica, se puede corroborar la consolidación del carácter representativo y monumental que el edificio carcelario había adquirido en el siglo XVIII (Fig. 5). Sin embargo, a diferencia de cárceles dieciochescas como la de Ferrol, ahora nos encontramos con una construcción en un neoclasicismo tardío pero más rotunda e imponente en su volumetría, con un efectista manejo de recursos plásticos como el almohadillado de las pilastras en los esquinales o las placas en resalte sobre el muro. En el interior se aprecia el esquema distributivo en torno al patio central ya conocido, con un pórtico inferior abierto en arcos y galería con ventanas superior, originalmente descubierta según Madoz. A diferencia de los ejemplos anteriores contaba con calabozos bien ventilados por las amplias ventanas abiertas al exterior. Abandonada en su uso como cárcel desde hace años, y por ello en creciente deterioro, hoy en día es un inmueble olvidado en el mismo corazón de Ourense.

En cuanto a la cárcel de Pontevedra, también se construirá para sustituir a un recinto muy inadecuado como era la situada en el Puente del Burgo pese a su reedificación de 1753. En este caso un primer proyecto saldrá en 1816 de la mano del arquitecto académico Melchor de Prado y

${ }^{38}$ A.H.P.O. Libros de Actas Municipales, año 1836, folios 85, 87, 90 y 91. Tras rematarse las últimas obras de puertas, ventanas, rejas y tejado en Septiembre de 1837 serían trasladados los presos.

${ }^{39}$ MADOZ, P. (1847), Tomo IV, 932.

"CUADERNOS DE ESTUDIOS GALLEGOS", Tomo XLVI, Fascículo 111, Santiago 1999. 


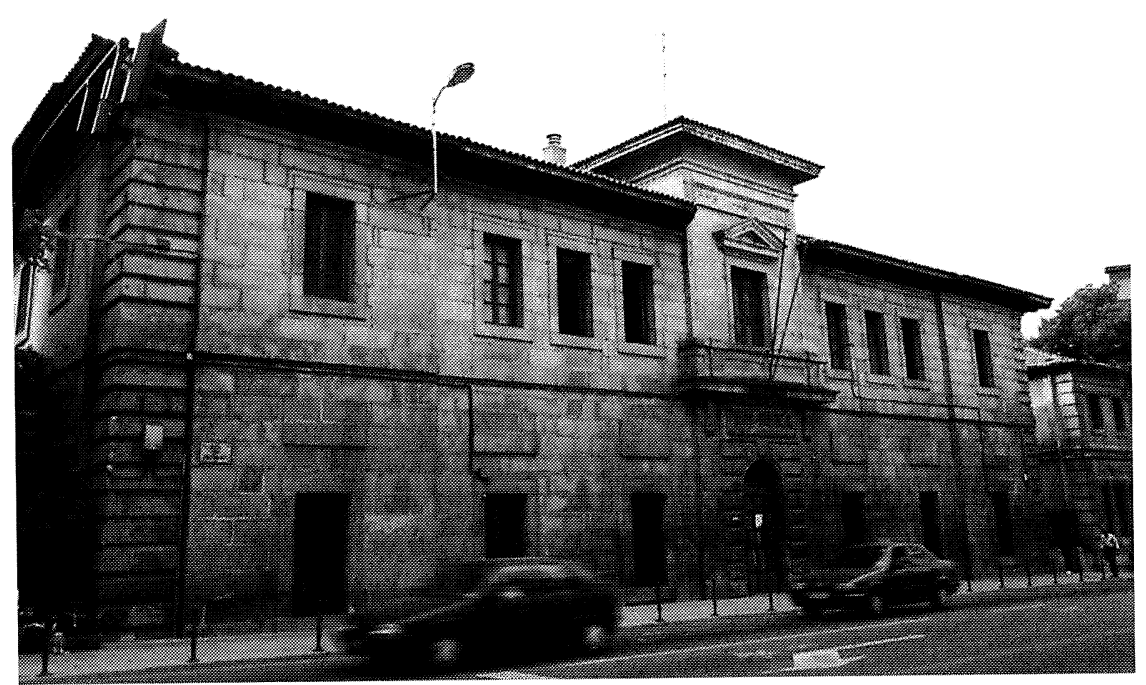

Fig. 5.- Ourense. Antigua Cárcel Provincial. 1836.

Mariño, manifestando la antigua cárcel pública y la que con mayor amplitud se intentaba construir ${ }^{40}$. Otra vez las dificultades presupuestarias harían caer el asunto en el olvido hasta que en 1850 el arquitecto municipal José García Limeses presentó ante la Academia el proyecto definiti$\mathrm{vo}^{41}$. Para esta cárcel se habían barajado anteriormente diversas ubicaciones como los desamortizados edificios de los Jesuitas, Santo Domingo o las Torres Arzobispales, prefiriéndose desde 1846 construirla de nueva planta en el Campo de San José. Las obras se verificaron de 1852 a 1854 bajo la supervisión del propio Limeses, con financiación estatal y participación del resto de ayuntamientos del Partido judicial ${ }^{42}$.

${ }^{40}$ A.R.A.B.A.S.F. Actas Sección de Arquitectura. Libro 1806 a 1823. Junta del 23 de Marzo de 1816, fol. 79. Sus dos planos y siete dibujos, perdidos, presentaban una construcción calculada en 413.951 reales. Recogido también en OTERO TÚÑEZ, R. (1969), 126 a 139; y bibliografía de la nota 8 .

${ }^{41}$ A.R.A.B.A.S.F. Actas Sección de Arquitectura. Libro 1846 a 1852. Junta del 27 de Agosto de 1850, fol. 198. Este arquitecto, natural de Pontevedra y titulado en 1842, ejercería el cargo hasta 1857, realizando también el primer proyecto para el Teatro Principal, sobre la antigua iglesia de San Bartolomé, o el Lazareto de San Simón.

42 Véanse las referencias en FORTES BOUZÁN, X. (1993), 615.

"CUADERNOS DE ESTUdIOS GALLEGOS", Tomo XLVI, Fascículo 111, Santiago 1999. 
Del edificio tan solo se conservan algunas fotografías antiguas ya que en nuestro siglo fue derribado al construirse una nueva cárcel en la zona de A Parda, y en su solar se ubica actualmente la Audiencia Provincial (Fig. 6). A través de los testimonios fotográficos, y a falta de planos que recojan exactamente su distribución interior, podemos afirmar que se trataba de un gran inmueble cúbico, de aspecto macizo, que conjugaba la sillería en el basamento, esquinales y recercado de vanos con la mampostería encalada del grueso de la fábrica. Su pesada y monótona imagen, cercana a los cuarteles militares por las rítmicas series de tragaluces y ventanales abiertos en sus muros, sólo se animaba con algunos resaltes de planos o el edículo de remate de la fachada principal. En suma, era una construcción bastante más pobre en sus recursos que la ya vista de Ourense, aunque sin perder una presencia masiva y la tradicional organización interior centrada por un patio cuadrado.

Sin salir del segundo tercio del siglo XIX, otras construcciones de nueva planta fueron las Cárceles de Partido surgidas con la reorganización de los primeros niveles del sistema penal derivada de la nueva división provincial puesta en marcha en 1833. Así, las cuatro diputaciones gallegas impulsarán desde los años 50 la construcción de estas cárceles para hacer frente a las necesidades de las localidades de menor entidad, ya que además de los depósitos o cárceles municipales cada Partido Judicial, que agrupaba a varios ayuntamientos, debía estar dotado en su cabecera con una cárcel de tamaño medio en la que también pudiera alojarse, para economizar gastos, el Juzgado de primera instancia correspondiente, y a veces incluso el Ayuntamiento ${ }^{43}$.

Al igual que ocurrió en otras provincias como en la vecina Asturias, en Galicia se adoptó un modelo de cárcel sencillo, de reducidas dimensiones y bajo coste, proyectadas para todos los Partidos judiciales salvo aquellos de criminalidad más reducida. En los casos donde el proyecto no llegó a materializarse el motivo estribó en las dificultades económicas ya que los municipios, constituidos en Junta Carcelaria, debían anticipar una

${ }^{43}$ Por otra parte, dentro del perfil delictivo de la España del XIX si bien en general las provincias gallegas no se encontraban en el grupo de cabeza en cuanto a criminalidad, sí compartían la alta tasa común a otras zonas agrícolas poco desarrolladas de la Península

"CUADERNOS DE ESTUDIOS GALLEGOS", Tomo XLVI, Fascículo 111, Santiago 1999. 


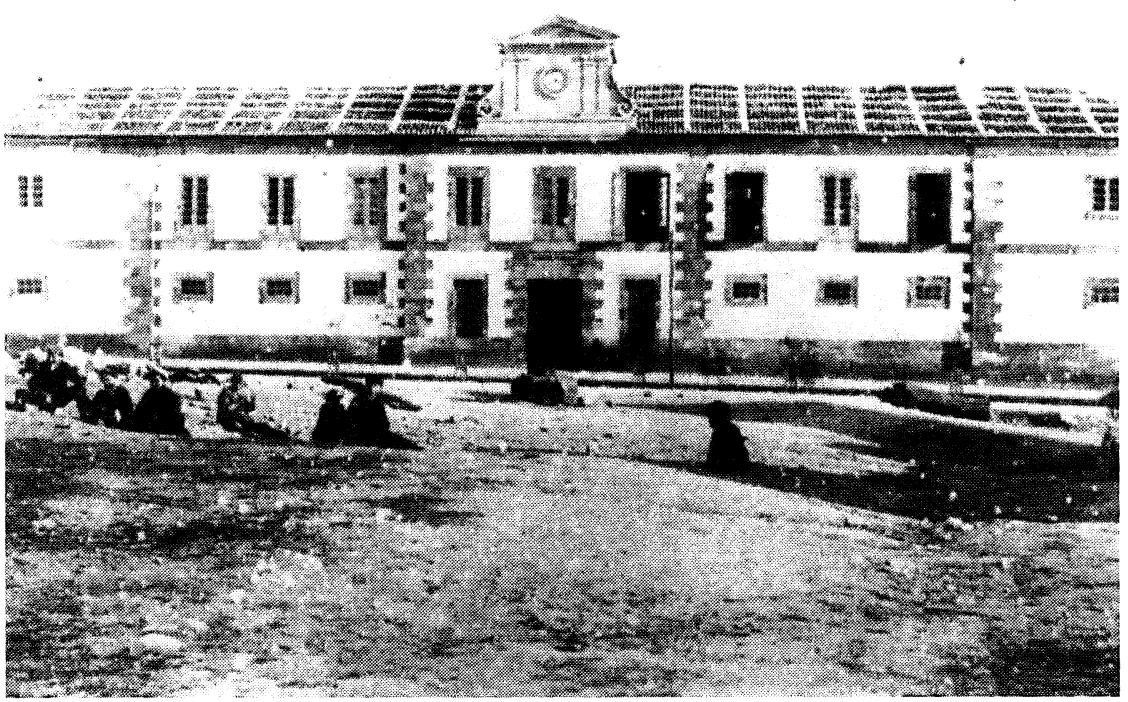

Fig. 6.- Pontevedra. Antigua Cárcel Provincial. 1850-1854. (Museo de Pontevedra).

buena proporción de los gastos, luego reintegrados por la Diputación y el Estado, no siendo capaces de allegar suficientes recursos, o bien relegando el proyecto por disponer de algún edificio más o menos conveniente.

En un proceso que también para toda España se desarrolló entre los años 50 y 60, fueron las provincias de Coruña y Lugo las que mayores esfuerzos volcaron, llegándose en el primer caso a conferirle tal prioridad dentro de las obras públicas que se logró articular una red que abarcaba el $60 \%$ de las cabeceras. La tarea de concretar arquitectónicamente este programa no podía recaer más que en los respectivos arquitectos provinciales. Sin embargo, dado que sólo la Diputación de A Coruña contaba desde 1846 con facultativo propio, el leonés afincado en Galicia Faustino Domínguez Domínguez (1817-1890) ${ }^{44}$, sus servicios fueron igualmente

${ }^{44}$ Sobre esta figura, sin duda la más interesante de la arquitectura gallega en los años centrales del siglo XIX, y su trayectoria desde el neoclasicismo al eclecticismo, véase MEIJIDE PARDO, A. (1989), 52 a 59; VIGO TRASANCOS, A. (1990), 330 Y 331; FERNÁNDEZ FERNÁNDEZ, X. (1995), 365 a 475; LÓPEZ VÁZQUEZ, J.M. (1995), 141 a 143; y nuestro trabajo SÁNCHEZ GARCÍA, J. A. (1995), 313 a 337.

"CUADERNOS DE ESTUDIOS GALLEGOS", Tomo XLVI, Fascículo 111, Santiago 1999. 
reclamados por las diputaciones de Lugo y Pontevedra en tanto no dispusieron de arquitectos propios, por lo que nos centraremos prioritariamente en las cárceles por él proyectadas.

Lugo y Pontevedra fueron las provincias que primero dieron inicio a la construcción de sus Cárceles de Partido al enviar entre 1849 y 1850 a la Academia de San Fernando los proyectos para las de Viveiro, de Faustino Domínguez, Ponte Caldelas y Cambados, debidas a José Moreno y Teixeira, y Tui, también de la autoría de Domínguez ${ }^{45}$. Dado que la de Viveiro no llegó a construirse, sí sabemos que a partir del tipo establecido en el proyecto para Tui Domínguez diseñará hasta 1854 las repartidas por Coruña y Lugo (Pontedeume, Negreira, Noia, Ortigueira, Muros, Arzúa, Betanzos, Carballo, Corcubión, Melide, Becerreá, Ribadeo, Quiroga y Chantada), planteando insistentemente pequeñas construcciones de una o dos alturas con patio central y forma tendente al cuadrilátero, con lo cual no estaba haciendo otra cosa que acomodarse al modelo de filiación dieciochesca que ya hemos analizado ${ }^{46}$. A pesar de los años transcurridos y los cambios de función hoy son todavía fácilmente reconocibles puesto que siempre se configuran como un bloque cúbico con una imagen clasicista muy sobria y normativizada de acuerdo con los principios académicos más básicos de simetría, axialidad y adaptación del carácter del edificio a su función (Fig. 7). Su fábrica, salvo el caso de Tui, acude siempre a la mampostería encalada, reservando la sillería para esquinales, cuerpo central de la fachada y recercado de vanos, buscando pues conjugar el máximo ahorro en los materiales con el mantenimiento de una cierta calidad edilicia, como correspondía a un edificio oficial.

Además, por su doble función original como Cárceles y Juzgados de Partido debían combinar una imagen sólida y firme con un aire represen-

${ }^{45}$ A.R.A.B.A.S.F. Sección de Arquitectura. Juntas del 22-V-1849, 12-VII-1850 y 27-VIII-1850. Posteriormente, en Abril de 1851 el mismo José Moreno presentará el proyecto para la cárcel de A Cañiza, y en Junio Manuel de Prado y Vallo, arquitecto municipal de Santiago, hará lo propio con la de Ordes.

${ }^{46}$ Tomando como comparación el caso de Asturias, estudiado por José Ramón Alonso Pereira, las mismas cárceles, construidas entre 1846 y 1862 con planos del arquitecto provincial Andrés Coello, adoptaron mayoritariamente una estructura longitudinal o de pabellón, con doble crujía interior y ordenación ternaria exterior, con un cuerpo central y dos alas laterales, que sólo en las poblaciones mayores giraba sobre si misma hasta configurar un cuadrilátero con patio central. ALONSO PEREIRA, J. R. (1985), 56 a 61.

"CUADERNOS DE ESTUDIOS GALLEGOS", Tomo XLVI, Fascículo 111, Santiago 1999. 


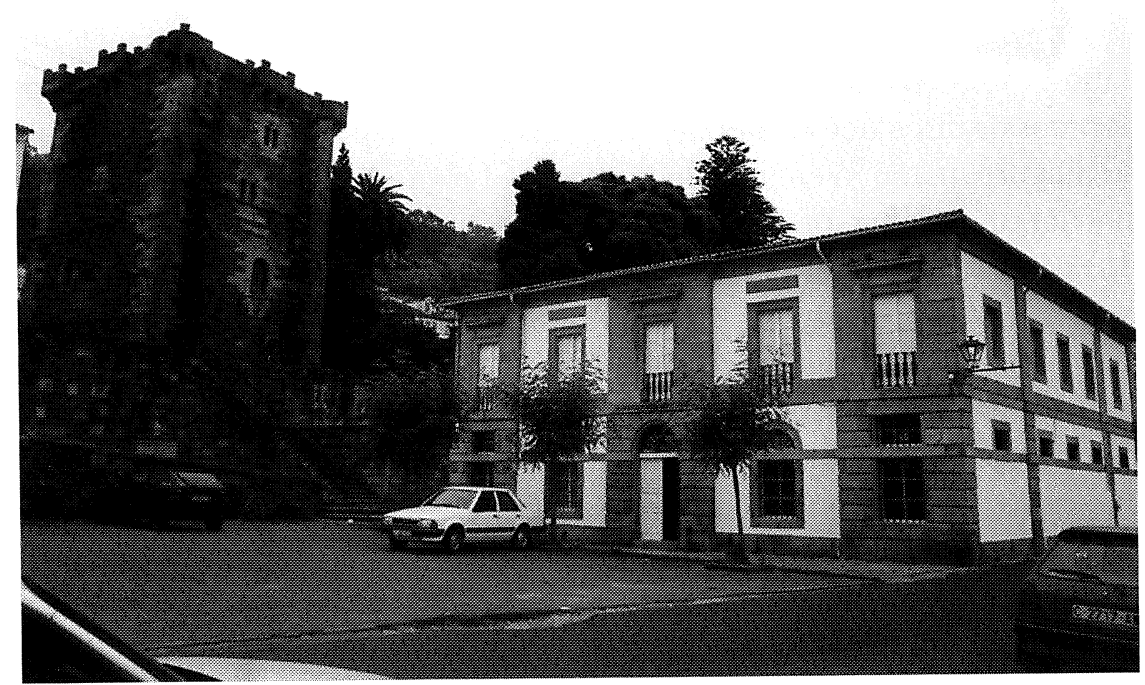

Fig. 7.- Pontedeume. Cárcel de Partido (1853-1856).

tativo, institucional, por lo cual el impacto de toda cárcel como pieza fundamental del aparato represivo estatal, revestida de una arquitectura imponente que transmitiera el mensaje de inexorabilidad de la justicia ${ }^{47}$, está suavizado por la adopción de pautas y léxico arquitectónico académicos. De este modo el almohadillado de los sillares y las rejas en las ventanas, que marcan la personalidad del edificio en la planta baja, se ven contrarrestados por unas fachadas jerarquizadas y distribuidas según el tradicional esquema tripartito de cuerpo central y alas laterales: unas veces insinuado por el reparto de vanos y bandas pétreas, otras remarcado por los planos salientes de cada cuerpo. En suma, se trata de unas construcciones muy austeras, incluso con cierto tono castrense, en las que las únicas licencias ornamentales se reducen a la presencia de los balcones

${ }^{47}$ Más adelante nos detendremos en la repercusión de reflexiones ilustradas como las de Jeremy Bentham acerca del papel del castigo hacia la consecución de una sociedad mejor y su influencia en la concreción de una arquitectura penitenciaria que también con su organización e imagen colaborara a conseguir la reforma de los presos y la sumisión ciudadana. FRAILE, P. (1989), 127 a 142.

"CUADERNOS DE ESTUDIOS GALLEGOS", Tomo XLVI, Fascículo 111, Santiago 1999. 
sobre la puerta central, las molduras de los ventanales principales o sus guardapolvos y tarjetones superiores.

En su organización interior las celdas se distribuyen en torno a un patio central reducido, a veces con pozo central, pero muy raramente con pórticos de circulación laterales, que todo lo más aparecen en las cárceles de mayor tamaño, o en un solo tramo en el resto. Los calabozos introducían en su distribución la exigencia de separar a los presos según su edad o sexo: destinando los del piso bajo para hombres y los del superior para mujeres, junto con alguna celda para incomunicar presos, cocina, enfermería y unos comunes o servicios. En el lado opuesto a la fachada principal siempre se reservaba un espacio más destacado, en el eje axial del edificio, para la capilla: elemento indispensable para la corrección moral de los presos, que podían asistir a la misa desde sus celdas. Las dependencias judiciales y administrativas se ubicaban en la crujía de la fachada principal, en la planta superior, mientras que en la baja iban las habitaciones del alcaide y cuerpo de guardia, junto con la escalera principal de comunicación de ambos niveles. Como emplazamiento se eligieron preferentemente terrenos excéntricos pero dentro de un radio de un kilómetro del núcleo de la villa para así alejar a los presos del contacto cotidiano con la población pero sin dificultar el acceso: casos de Tui, Carballo, Negreira, Arzúa o Ribadeo; otra opción fue la de terrenos de ribera en el mismo borde urbano para aquellas villas costeras como Ortigueira, Corcubión o Pontedeume ${ }^{48}$. Otras cárceles proyectadas coetáneamente por distintos arquitectos, pero muy próximas al modelo establecido por Domínguez fueron las de Caldas, A Cañiza, Ordes, Carballiño, Ribadavia, Lalín, Allariz, Chantada, Quiroga y Becerreá.

Frente a la escasa entidad arquitectónica de cada una de estas cárceles tomada aisladamente, es preciso destacar que el programa edilicio desarrollado por Faustino Domínguez desde 1849 a 1854 constituye la primera y más completa iniciativa abordada en el siglo XIX para dotar al territorio gallego de una arquitectura institucional racionalmente distribuida,

\footnotetext{
${ }^{48}$ Las que finalmente llegaron a construirse en las localidades reseñadas se mantienen hoy en pie con escasas transformaciones dado que por sus dimensiones y distribución resultaron con el tiempo, al suprimirse las cárceles de partido en 1931, idóneas para albergar las sedes o servicios municipales de unas villas de mediana importancia.
} 
seriada y siempre acomodada a un mismo tipo, en un empeño que no tendrá continuidad con otras dotaciones también urgentes como las mismas escuelas. No es casual la fecha de arranque de este proceso porque la Ley de régimen general de prisiones, cárceles y casas de corrección aprobada el 26 de Julio de 1849 indicará ya en su artículo 25 dos criterios, al margen del sexo, para separar a los presos en distintos departamentos: primero según la naturaleza de sus condenas, aislando a los sentenciados por causas políticas, y segundo por la diferencia de edad dentro de los que tuvieran la misma condena, separando a los adultos de los menores de 18 años si eran varones, y de 15 si eran mujeres. De acuerdo con ello tanto en las Cárceles de Partido como en las de Audiencia habría departamentos diferentes para hombres y mujeres, separando en cada sexo a los menores, además del aislamiento de los presos políticos del resto. Una última recomendación, contenida en el artículo 11, se refería a la necesidad de procurar igualmente que si los edificios lo permitían se separara a los presos con causa pendiente de aquellos que estuvieran cumpliendo condena de arresto mayor.

Se trataba, sin duda, de importantes avances con respecto a la situación anterior, aunque en realidad habrá que esperar hasta el Programa para la construcción de las cárceles de provincia y para la reforma de los edificios existentes destinados a esta clase de establecimientos, aprobado en 1860 , para encontrar una normativa global que clasificara y recomendara opciones para configurar los distintos espacios penitenciarios. Aunque por su fecha más tardía esta norma no llegó a incidir sobre las Cárceles de Partido gallegas, sí queremos resaltar que todavía mantenía la fórmula del confinamiento en «cuadras», rechazando el celular por incrementar demasiado los costos del edificio, por lo que aún aceptando su idoneidad sólo lo recomendaba aplicar en los depósitos municipales y para reos pendientes de causa ${ }^{49}$.

Finalmente, la segunda mitad del siglo XIX supondrá la ruptura con el modelo de cárcel dieciochesco, por lo que a partir de 1860 ya podremos

${ }^{49}$ FRAILE, P. (1989), 161. Sí se incorporarán avances al establecerse los metros cúbicos necesarios para cada individuo, la relación superficie total/número de confinados, la necesidad de talleres de trabajo o de un punto de vigilancia central combinado con una disposición radial de las galerías, recogiendo parte de la teoría del panóptico de Bentham como abordaremos a continuación.

"CUADERNOS DE ESTUDIOS GALLEGOS", Tomo XLVI, Fascículo 111, Santiago 1999. 
rastrear en la arquitectura penitenciaria gallega la recepción de las más modernas tendencias europeas e hispanas. Estas ya eran conocidas desde años atrás gracias a dos publicaciones trascendentales como fueron la Descripción de los más célebres establecimientos penitenciarios de Europa y América de Marcial Antonio López (1832), y sobre todo el Atlas Carcelario de Ramón de la Sagra (1843). Sin embargo, estos repertorios carecerán de repercusión en la legislación penitenciaria española hasta el año 1860, cuando unas primeras tentativas de modernización se recojan en el Programa para la construcción de las cárceles de provincia... ya mencionado. Con vistas a elaborar esta norma una Real Orden del 23 de Julio de 1859 había decretado la necesidad de visitar las cárceles del extranjero para comprobar la eficacia de sus sistemas de reclusión, comisionando para ello a D. Francisco Murube y Galán, profesor de derecho penal y mercantil precisamente en la Universidad de Santiago de Compostela. Este estudioso con sus apuntes de viaje y otros informes oficiales ya manejados por de la Sagra redactaría un poco conocido Tratado de las prisiones y sistemas penales de Inglaterra y Francia $(1860)^{50}$. Todas las obras y legislación citadas serían completadas hasta final de siglo con los modelos propuestos por Juan Madrazo y otros prestigiosos arquitectos, a veces presentados ante la Escuela de Arquitectura, y finalmente recogidos en los ejemplos de cárceles suministrados en el exhaustivo Anuario Penitenciario de 1889.

Por lo tanto, será en esta segunda mitad del siglo XIX cuando España recoja en su legislación y praxis constructiva propuestas esenciales como las de Jeremy Bentham (1748-1832): hombre de leyes inglés que ya a finales del Setecientos había sentado las bases de un sistema penitenciario orientado a regenerar al convicto, en el que la nueva concepción del edificio carcelario será una pieza fundamental al procurar su aislamiento y separación permanentes para así conseguir su solitaria reflexión y en-

\footnotetext{
${ }^{50}$ En esta obra su autor analiza las prisiones y sistemas penales de Inglaterra y Francia, con ejemplos de las construcciones más notables, además de recoger en un apéndice final las ideas de Howard, la propuesta de panóptico de Bentham o una tabla con la legislación penal española desde 1833. En sus conclusiones propone adecuar el número de presidios españoles a la cantidad de condenas dictada anualmente, siendo necesario para ello disponer de 1.304 establecimientos, en los que se alojarían hasta un máximo de 20.000 condenados.
} 
mienda ${ }^{51}$. Su modelo de cárcel que denominará panóptico y dará a conocer en 1791 (Panopticon or the inspection house), se configuraría como un edificio circular de varias plantas, con una organización anular en la que una torre central posibilitaría que un solo vigilante pudiera controlar todas las celdas radiales, dispuestas como en una colmena y abiertas a su vista al cerrarse solo con una reja de hierro; en cambio, la invisibilidad del vigilante por estar oculto tras unas celosías, introduciría en los presos la conciencia de estar permanentemente observados, sin posibilidad de escapar a la mirada del poder, y por tanto sometidos sin remisión ${ }^{52}$.

Muy escasas fueron las cárceles que se construyeron según esta teoría por su alto coste y baja capacidad en la ocupación de presos: Richmond en Estados Unidos (1797) o la de Devizes en Inglaterra (1817). Ahora bien, sus fundamentos arquitectónicos conocerían gran expansión por toda Europa y América, influyendo decisivamente en la renovación del espacio carcelario tradicional ${ }^{53}$. Así, el principio de la inspección central sería aplicado a cárceles constituidas por galerías radiales en las que se renuncia a vigilar el interior de cada celda en favor del control de lo que ocurre en el corredor central de los diferentes pabellones. Con ello la organización radial de las prisiones, tomada de los hospitales y ya preconizada en construcciones dieciochescas como la Maison de Force de Gante (177275), con ocho pabellones sin corredor central pero unidos en un patio central octogonal, se perfeccionó con la teoría del panóptico y su «centro de observación» hasta dar lugar a cárceles con brazos en $\mathrm{Y}$, en T, en cruz,

${ }^{51}$ Estas ideas continuaban en parte las esbozadas por John Howard (1726-1790), el primero en defender la clasificación de los presos según sus delitos y el aislamiento como forma de actuar sobre su conciencia para llegar hasta su arrepentimiento. Sobre la figura de Howard y sus ideas genéricas para mejorar las características de una cárcel, incluyendo patios, baños, enfermería, capilla, véase: MOSQUETE, D. (1957), 15 a 18;

${ }^{52}$ Sobre las características del panóptico, también aplicables según su autor a construcciones como correccionales, manicomios, hospitales, fábricas, escuelas, pueden consultarse los trabajos de CASTELLÓN, J. (1945), 91 y 92; GARCÍA BASALO, J. C. (1957c), 589 a 594; PEVSNER, N. (1979), 194 a 196; ARRECHEA MIGUEL, J. (1988), 88 a 109; y FRAILE, P. (1989), 39 a 53 y 131 a 142.

${ }^{53}$ Este modelo sería trasladado a España en publicaciones como las de Villanueva y Jordán: Aplicación de la Panóptica de J. Bentham a las cárceles y casas de corrección de España (1834) o el Informe sobre las doctrinas de Bentham; Toribio Núñez, Ciencia Social según los principios de Bentham (1835); y Ventura Arquellada, Noticia de la cárcel de Filadelfia.

"CUADERNOS DE ESTUDIOS GALLEGOS", Tomo XLVI, Fascículo 111, Santiago 1999. 
en abanico, o en estrella. Esta sería, pues, la fuente de inspiración de algunas de las cárceles más importantes de principios del XIX como la penitenciaría del Este de Filadelfia (J. Haviland, 1825), donde sus siete pabellones radiales parten de una rotonda central que no obstante va perdiendo su función de vigilancia al ganar protagonismo las celdas ya individuales, separadas por un corredor central ${ }^{54}$.

Partiendo de estas experiencias europeas y americanas, desde los años 60 del siglo XIX en adelante en Galicia se asentará una arquitectura carcelaria ya con sentido correctivo, asumiendo la idoneidad de los principios de la clasificación y el confinamiento celular que se avanzaban en la normativa de 1860. Ahora los nuevos recintos se plantearán siguiendo el referido sistema mixto: con soluciones radiales antes que panópticas, por ser las que permitían alojar mayor número de presos y hacer más rentable la construcción. En estas cárceles radiales el punto central de vigilancia frecuentemente se sustituirá o compatibilizará con una capilla sobreelevada para que los presos situados en el corredor delante de sus celdas pudieran asistir a los oficios. Por último, en su imagen de cara a la ciudad corrientemente renunciarán a aquellas fachadas rotundas y masivas vistas hasta aquí, perdiendo carga semántica en favor de concepciones más funcionales derivadas de la idea de edificio-máquina contemporánea.

De acuerdo con estos postulados es como conviene valorar nuestras mejores cárceles decimonónicas, entre las que destaca en primer lugar la de Vigo (Fig. 8). El nuevo edificio sustituía a la antigua, «de escasa comodidad y poco espaciosa» según Madoz, pero con la idea de simultanear su función con la de Palacio de Justicia, lo que explica su cuidada presencia externa en una de las calles más céntricas de la ciudad como es la de Príncipe. Esta cárcel supondrá además la primera concreción en Galicia del sistema mixto de cárceles radiales con punto central de vigilancia. El

${ }^{54}$ GARCÍA BASALO, J. C. (1957b), 771 a 778. Paralelamente también en los Estados Unidos se desarrollaría la fórmula alternativa del sistema de pabellones a los lados del bloque administrativo, con celdas celulares en cada uno, con punto de partida en la prisión de Auburn (Nueva York, 1815-25). En cuanto a Europa, ya a finales de siglo el sistema radial sería desplazado por las prisiones con pabellones colocados en paralelo entre sí pero perpendiculares a un corredor principal, sistema «en paralelo», menos caro en su construcción y susceptible de ampliaciones sin mayores problemas.

"CUADERNOS DE ESTUDIOS GALLEGOS", Tomo XLVI, Fascículo 111, Santiago 1999. 


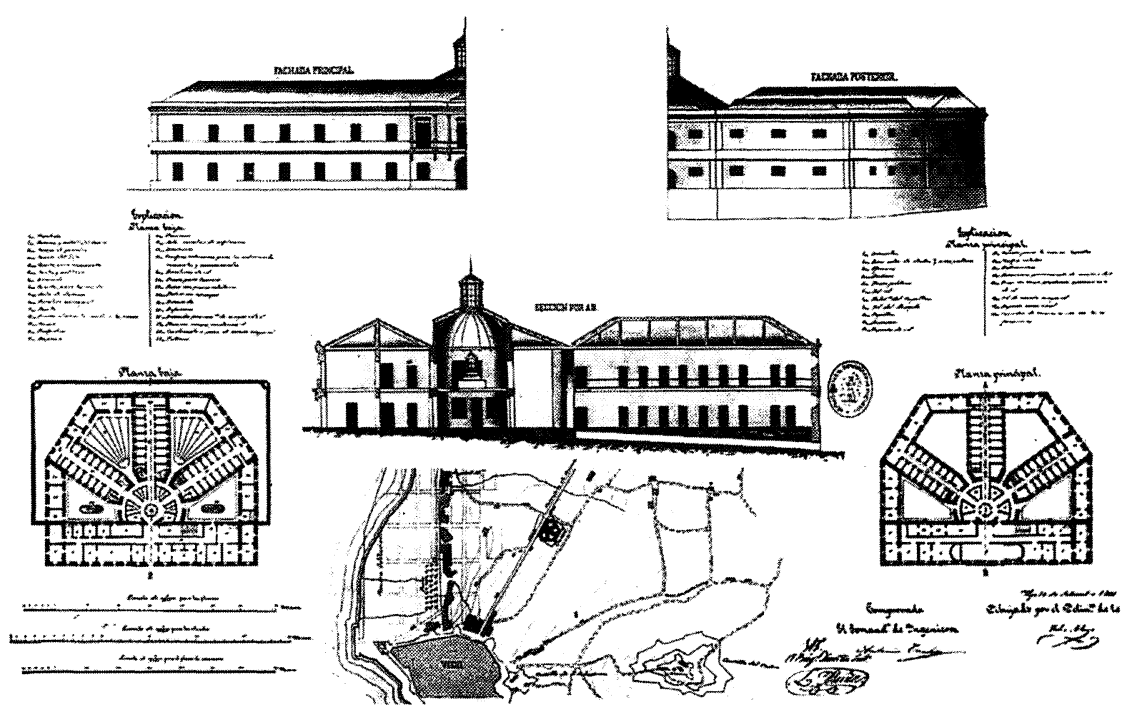

Fig. 8.- Vigo. Palacio de Justicia y Cárcel. 1861-1880. (Fuente: GARRIDO RODRÍGUEZ, J. 1991).

proyecto fue redactado en 1861 por el arquitecto provincial, creemos que el madrileño y académico José María Ortiz, a instancias de una Real Orden del 16 de Mayo de 1861 que venía a eliminar las carencias de la vieja y lóbrega cárcel situada en la zona del mirador de la Piedra, detrás de la Pescadería ${ }^{55}$. Sin embargo, en la dirección de obras a partir de 1865 intervendrían Juan Ancell, y sobre todo entre 1878 y 1879 Justino Flórez Llamas, entonces arquitecto municipal de Vigo.

Sobre un gran solar hexagonal que durante las obras se vería progresivamente flanqueado por la edificación de viviendas en lo que en un principio fue el arranque de la carretera a Ourense, la cárcel dispone una primera crujía rectangular y paralela a la calle, de 66 metros de largo, donde se alojan las dependencias judiciales y administrativas. A continuación se sitúa la sala semicircular de vigilancia, de la que parten los

\footnotetext{
${ }^{55}$ La referencia más completa a la nueva cárcel de Vigo, con la publicación de sus planos y fotografías en unos años en que peligraba su continuidad se encuentra en el valioso trabajo de GARRIDO RODRÍGUEZ, J. (1991), 219 a 230.
}

"CUADERNOS DE ESTUDIOS GALLEGOS", Tomo XLVI, Fascículo 111, Santiago 1999. 
tres brazos de galerías, unidas en sus extremos por un cuerpo periférico que abarca los cinco lados externos del inmueble. Otra de las novedades introducidas es la del sistema de confinamiento celular, aislando a cada recluso en su celda, pero a la vez completado con una noción de clasificación al dividir a los reclusos en categorías, y una atención a las zonas de esparcimiento, con cuatro grandes patios comunes.

Al exterior la doble función del edificio se decanta por una fachada representativa y ecléctica que alude más explícitamente a la condición de Palacio de Justicia por incluir una placa de mármol con este epígrafe y el año de puesta en uso, 1880. Por esta razón se recurre a una serie de elementos de la arquitectura oficial muy típicos también de ayuntamientos y diputaciones como el basamento inferior en sillería, la escalinata, el resalte del cuerpo central con respecto al plano de fachada, su tratamiento almohadillado, el balcón principal acompañado de pilastras o el ático superior con reloj. El resto de fachadas, como ha observado Jaime Garrido, son más pesadas y pobres en cuanto a recursos dignificadores, con lo que claramente se adecúan a una concepción más pragmática del espacio carcelario que encierran.

Otro hito importante es el proyecto de Cárcel para Betanzos diseñado en 1865 por Faustino Domínguez Domínguez, sucediendo a la cárcel de Partido planificada en el año 1853 pero que nunca había llegado a construirse $^{56}$. Ahora Betanzos seguía sin precisar una cárcel de grandes dimensiones, pero su situación en la carretera de Coruña a Madrid le confería la categoría de depósito apto para presos en traslado. Se eligió como ubicación un terreno a las afueras, cerca de la calle del Rollo, propiedad de D. Faustino Sanmartín, donde luego se construirían las Escuelas García Naveira, con la ventaja de encontrarse algo elevado lo que le aseguraría la ventilación. Según las directrices del programa de 1860, completado con las mejoras más sobresalientes de Europa y los Estados Unidos en otra disposición de 1863, Domínguez plantea ahora frente a sus proyectos anteriores una cárcel celular y con planta radial ${ }^{57}$. Estaría constituida

${ }^{56}$ Sobre este proyecto y sus planos se encuentra una breve noticia en MOLINA TABOADA, C. (1986).

${ }^{57}$ Por su interés para las introducción de la nueva concepción del edificio carcelario en Galicia hemos de reseñar que ya anteriormente, entre 1857 y 1859, Domínguez trabajaría en un nuevo proyecto para el Presidio de A Coruña, ahora con doble carácter, Pe-

"CUADERNOS DE ESTUDIOS GALLEGOS", Tomo XLVI, Fascículo 111, Santiago 1999. 
por dos crujías principales, de hombres y mujeres, que van a confluir a un núcleo hexagonal con el centro de vigilancia abajo y la capilla sobre columnas y plataforma de fundición encima (Fig. 9). Esas dos galerías se subdividen en varias secciones, cada una con su patio, en el que bajo unos cobertizos se sitúan los comunes o servicios. Otra crujía previa, con dos alturas, contendría los servicios administrativos y enfermería en planta baja, junto con la prisión de presos políticos y sala para tomar declaraciones en la superior.

De acuerdo con los avances ya recogidos en la normativa se incluyen también talleres y locutorios, calculándose además los metros cuadrados que corresponderían de extensión superficial a cada uno de los 51 confinados $(46,09 \mathrm{~m} 2)$. Las dimensiones de las celdas de 3,90 metros de longi-

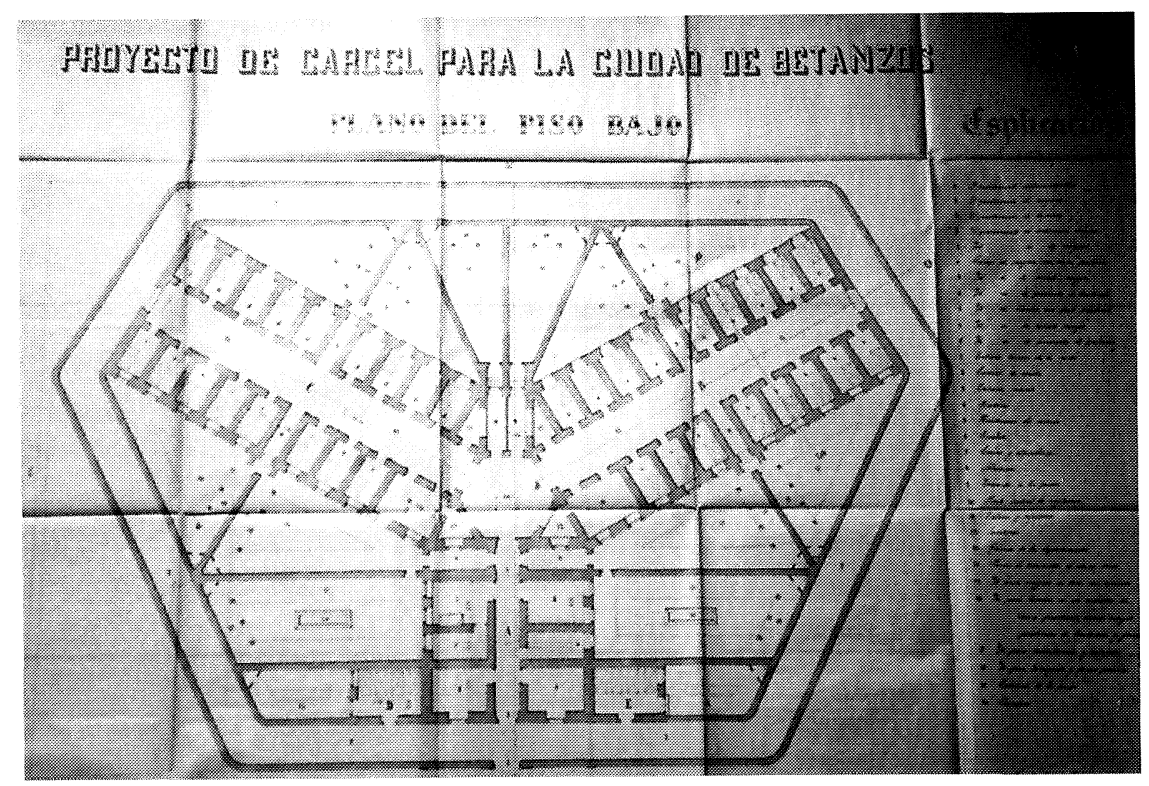

Fig. 9.- Betanzos. Proyecto de Cárcel (1865). A.H.D.P.C.

ninsular y Correccional, en el que ya se incorporaban unas primeras reflexiones sobre sus características arquitectónicas como medio para corregir las costumbres de los confinados. A pesar de perderse sus planos sabemos que contaba con locales suficientes para separarlos según la gravedad de sus delitos, talleres o una escuela. A.H.D.P.C. Libro de Actas años 1857-64. Año 1857, Sesión del 24 de Agosto.

"CUADERNOS DE ESTUDIOS GALLEGOS", Tomo XLVI, Fascículo 111, Santiago 1999. 
tud por 2,25 de ancho y 4 de alto satisfacían casi exactamente las recomendadas en los programas de 1860 y 1863 . Cada una contaba con su ventana elevada, puerta con postigo para alimentos y tubo de mirilla, abriéndose a los corredores interiores y nunca al camino de ronda externo para impedir cualquier comunicación. Aunque carecía de excusados individuales se aseguraba la ventilación de estas celdas por un sistema de tubos de barro cocido que iban a dar a unas tajeas subterráneas. Su construcción emplearía la mampostería y sillería, con materiales del país como la pizarra.

Lo más importante es destacar la plena asimilación de la forma radial conjugada con el punto de observación central tomado del panóptico de Bentham, por lo que según su autor se aseguraría una fácil vigilancia, el aislamiento de los presos y su asistencia a los oficios religiosos sin mezclarse. Al igual que para la Cárcel de Vigo podrían buscarse sus modelos en prisiones como la aludida del Este en Filadelfia o la parisina de la Santé (1862), aunque en este caso hay que destacar la coincidencia formal con el Depósito Municipal propuesto por el arquitecto madrileño Juan Madrazo a partir de la normativa de 1860 y recogido luego junto con otros diseños en el Anuario Penitenciario del año 1889. Sin embargo, el presupuesto que ascendía a 646.826rs tampoco en esta ocasión llegaría a permitir abordar su construcción, por lo que Betanzos mantuvo en uso hasta nuestro siglo la pésima cárcel de la calle del Rastro.

En cuanto a la Cárcel Provincial de Lugo, es una construcción más singular puesto que se trata de la más perfecta adaptación llevada a cabo en nuestra tierra del modelo del panóptico de Bentham, si bien reducido a un cuerpo semicircular en vez de desplegar un círculo completo ${ }^{58}$. Un primer proyecto de cárcel de Partido del año 1865 precedería al definitivo de Nemesio Cobreros (1871-1909), arquitecto provincial y municipal a partir de 1870 , firmado en 1878 . Construida entre 1882 y 1887 , vuelve a organizarse con un cuerpo alargado delantero que albergaría el Juzgado de instrucción, sólo de una planta y con portada destacada. A continua-

\footnotetext{
${ }^{58}$ De la misma se han ocupado X. Fernández y Abel Vilela, aunque ninguno ha llegado a calibrar suficientemente su originalidad tipológica. Además, el primero confunde la disposición radial y panóptica como cosas equivalentes, viendo por ejemplo en la reseñada cárcel de Vigo un ejemplo de panóptico. FERNÁNDEZ FERNÁNDEZ, X. (1995), 177 a 188; y ABEL VILELA, A. (1996), 181 a 186.
} 
ción un bloque de tres plantas rectangular alojaría los locutorios celulares, salas de espera y cuerpo de guardia en planta baja, dedicándose las otras dos a cárcel de mujeres. Finalmente, el cuerpo semicircular adosado contiene las celdas de hombres, otra vez en tres plantas, solo que ahora dispuestas radialmente y convergiendo hacia el patio central donde estarían el punto de vigilancia y la capilla superior (Fig. 10). Tras los patios otro bloque de una planta se dedicaba a cocina, almacenes, enfermerías y sala de autopsias.

Al margen de su singularidad tipológica, esta cárcel será una de las más completas de la época entre las existentes en las capitales de provincia por la atención con que fueron diseñados todos los detalles en cuanto a dimensiones de celdas, mobiliario o servicios higiénicos. Muy probablemente su arquitecto se inspiró en los modelos suministrados por el Atlas carcelario de Ramón de la Sagra, donde se encuentran proyectos de cárceles semicirculares, como una en concreto de 48 celdas; otra posible fuente sería la cárcel de Partido diseñada para la villa de Mataró por Elías Rogent en 1852 al tener la misma forma semicircular del cuerpo de celdas, a pesar de que aún mantenía el confinamiento en «cuadras». En la actualidad es la sede de la Policía Municipal y Cuerpo de Bomberos.

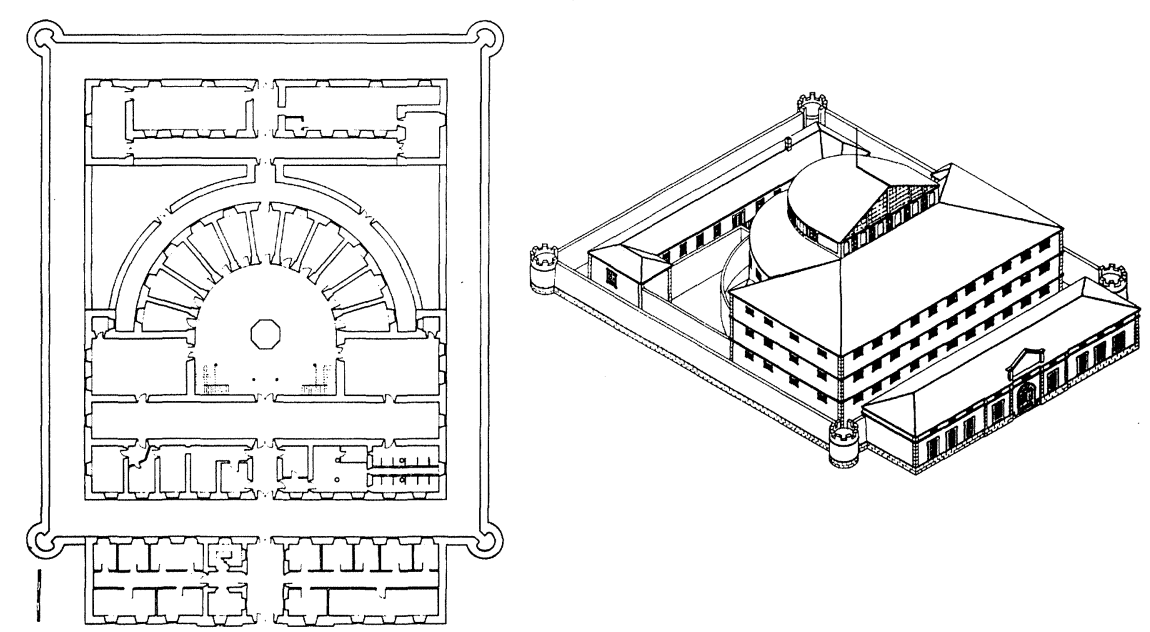

Fig. 10.- Lugo. Antigua Prisión Provincial. (Fuente: Fernández, X. 1995). (1878-1887). 
Finalmente, la Prisión Provincial de A Coruña, inaugurada en el año 1927, constituye dadas sus fuentes de inspiración un último hito en los penales decimonónicos que estamos abordando. La iniciativa para construir una «nueva cárcel pública que respondiese a las exigencias de la ciencia y de la ley», y sustituyese al »lóbrego e inhumano» edificio del Parrote, partió en 1894 del Alcalde Carlos Martínez Esparís ${ }^{59}$. Si en 1896 se constituyó ya la Junta de Inspección, Vigilancia y Administración de las obras de la nueva cárcel, hasta 1903 no se escogieron para su ubicación unos terrenos situados en el Campo de Marte, a la vez aislados pero de fácil acceso. Sin embargo, este primer proyecto no llegó a fraguar en ninguna propuesta arquitectónica ya que no se pudo asegurar la necesaria financiación estatal. Por ello, sólo en el año 1924 el Directorio Militar en el poder notificaría la concesión de créditos para abordar las obras, optándose porque el Ayuntamiento adquiriera de su presupuesto los terrenos necesarios, ahora en la carretera de circunvalación en las inmediaciones de la Torre de Hércules, que luego serían cedidos al Estado para construir la nueva cárcel ${ }^{60}$.

El arquitecto encargado de formar los planos para una cárcel llamada a ser de Audiencia, de Partido y Depósito Municipal fue Juan Álvarez de Mendoza, facultativo de la Dirección General de Prisiones a quien el arquitecto municipal de A Coruña, Pedro Mariño, enviaría planos y observaciones sobre el terreno elegido. El proyecto, fechado en Madrid en Enero de 1925, sería sin embargo sometido a posteriores modificaciones por Mariño, especialmente en lo que se refiere a las características del cuerpo situado en el acceso. Ahora bien, conviene destacar que ya desde los primeros planos de Mendoza se configuraban las características básicas de una cárcel con forma general de cruz en sus galerías, que sería la finalmente adoptada tras las obras (Figs. 11 y 12). Así, tras el cuerpo bajo y con porches para las visitas del acceso, dedicado a los servicios adminis-

\footnotetext{
${ }^{59}$ A.M.C. Obras Municipales. C-1036.

${ }^{60}$ Para la compra de esos terrenos hasta una extensión de 16.800 metros cuadrados se habilitó un crédito especial de 25.000 ptas. Con ello el proyecto recibió autorización gubernativa por R.O. publicada en la Gaceta del 22 de Noviembre de 1924. Además, al año siguiente se intentaría la misma operación en unos terrenos cercanos con vistas a construir una cárcel de mujeres para la que finalmente no se obtuvo financiación estatal, abortándose la idea.
} 


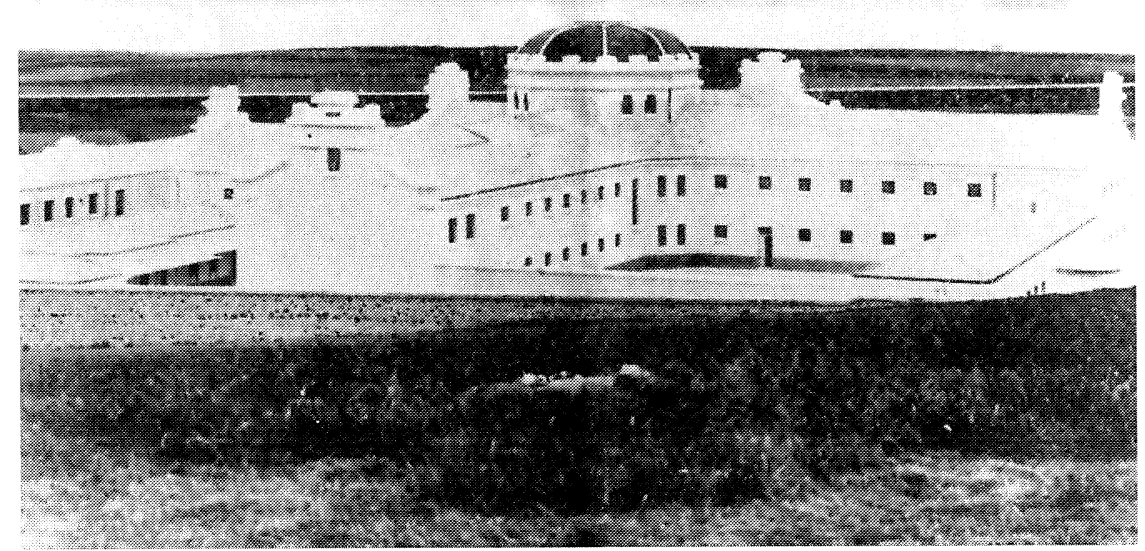

Fig. 11.- A Coruña. Prisión Provincial (1925-1927).

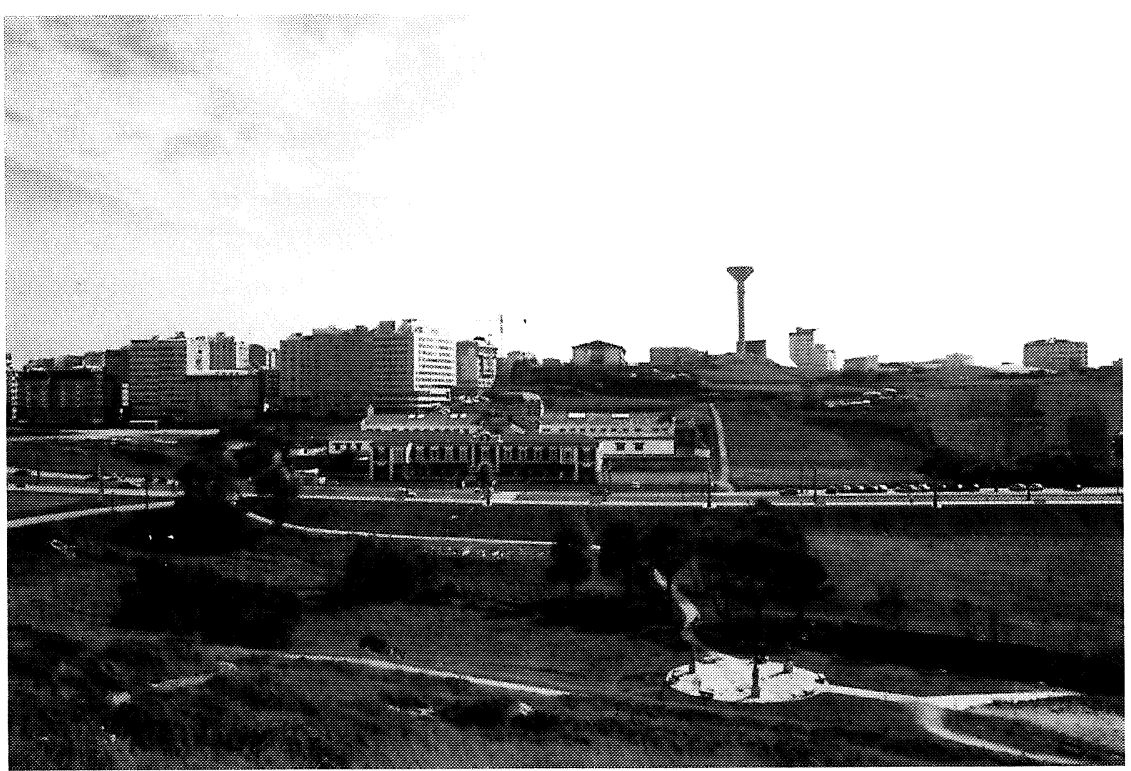

Fig. 12.- A Coruña. Prisión Provincial (1925-1927). 
trativos, se disponía un primer brazo o galería rectangular que a través de unos escalones desembocaba en el espacio o punto central de vigilancia; manteniendo una disposición típicamente decimonónica esta galería se destinaba para los calabozos de presos políticos y distinguidos, junto con una sala de Audiencia. En cambio, desde el espacio central ocupado por la plataforma del altar surgían los otros tres brazos de la cruz: ahora con forma trapezoidal para facilitar el ángulo de visión hacia su corredor y puertas de las celdas. Aquí estarían los departamentos celulares para presos comunes, con los aseos en los extremos, mientras que rodeando el núcleo central se ubicaban un archivo, sala de antropometría, sala de oficiales de guardia y la sacristía.

Esa forma general de cruz, y sobre todo la rotonda cupulada que cubre el espacio central de vigilancia, hacen bastante fácil la identificación de la fuente de inspiración manejada por el arquitecto de prisiones para esta construcción. Esta no era otra que la Cárcel Modelo de Barcelona: proyectada en 1880 por José Domenech y Salvador Viñals, e inaugurada en 1904, haciéndose eco toda la prensa del país de sus detalles e innovaciones. Aunque aquí la disposición de seis galerías en diagonal proporcionara una forma general de aspa, más compleja, podemos rastrear la misma solución en planta y alzado para el espacio central cupulado y con ventanas que proporcionaría abundante luz natural ${ }^{61}$. En resumen, todavía en la Cárcel de A Coruña es factible comprobar, al igual que en otras construidas coetáneamente, el alto grado de arrraigo de la solución radial conjugada con el punto de vigilancia central preferida en nuestra arquitectura penitenciaria decimonónica, pese a que ya desde principios del XX se impusiera tanto en Europa como en los Estados Unidos la alternativa del confinamiento en una estructura de pabellones.

${ }^{61}$ Además, la forma trapezoidal de las galerías remite a modelos como el proyecto de Tomás Aranguren recogido en el Anuario Penitenciario de 1889, si bien sólo con tres galerías y menores dimensiones.

"CUADERNOS DE ESTUdiOS GALLEGOS", Tomo XLVI, Fascículo 111, Santiago 1999. 


\section{FUENTES DOCUMENTALES Y BIBLIOGRAFÍA}

\section{Fuentes documentales}

Archivo Histórico de la Diputación Provincial de A Coruña.

Archivo Municipal de Betanzos.

Archivo Municipal de A Coruña.

Archivo Municipal de Pontevedra.

Archivo Municipal de Ourense.

Archivo de la Real Academia de Bellas Artes de San Fernando. Madrid.

\section{Bibliografía}

ABEL VILELA, A. de (1984): Cousas de Lugo. AVA, Lugo.

ABEL VILELA, A. de (1996): Urbanismo y arquitectura en Lugo. Arquitectura Isabelina y de la Restauración. Ediciós do Castro, Sada-A Coruña.

ALONSO PEREIRA, J.R. (1985): «La arquitectura penitenciaria en Asturias: de las cárceles de partido a la panóptica de Oviedo» en Boletín Académico de la ETSA de La Coruña, № 2 (56 a 61).

AMOR MEILÁN, M. (1930): «Provincia de Lugo» en Geografía General del Reino de Galicia, Vol. VIII (CARRERAS CANDI, F.). Ed. Alberto Martí, Barcelona (Reed. Ediciones Gallegas, La Coruña, 1980).

ARRECHEA MIGUEL, J. (1988): «La arquitectura de la represión en el siglo XIX: cárceles y manicomios» en Arquitectura y Orden. Ensayos sobre tipologías arquitectónicas. COA León-Univ. de Valladolid (89 a 109).

BANDE RODRÍGUEZ, E. y FERNÁNDEZ RODRÍGUEZ, L. (1993): Guía Histórico-Artística da cidade de Ourense. Concello de Ourense.

BARRAL RIVADULLA, M.D. (1995): «Alteraciones en la fábrica de la ex-iglesia conventual de San Francisco de La Coruña (1835-1991): desaparición, recuperación e invención» en Anuario Brigantino, $\mathrm{N}^{\circ}$ 18 (239 a 250).

"CUADERNOS DE ESTUDIOS GALLEGOS", Tomo XLVI, Fascículo 111, Santiago 1999. 
BONET CORREA, A. (1978): «Arquitectura carcelaria en España» en Historia-16. Extra VII, Octubre de 1978 (139 a 144).

BONET CORREA, A. (1984): Arquitectura en Galicia durante el siglo XVII. CSIC, Madrid.

CAINZOS CORBEIRA, A. (1995): «O cárcere do partido xudicial de Pontedeume (1853-1856): obra do arquitecto provincial Faustino Domínguez Domínguez» en Cátedra. Revista de Estudios Eumeses, $\mathrm{N}^{\circ} 2$ (63 a 74).

CARRE ALDAO, E. (1930): «Provincia de La Coruña» en Geografía General del Reino de Galicia... Vol. V.

CASTELLÓN, J. (1945): «El famoso panóptico de Bentham. Produjo honda transformación en el sistema de edificación de prisiones» en Revista de Estudios Penitenciarios, $\mathrm{N}^{\circ} 5$ (91 a 92).

COSTA BUJÁN, P. y MORENAS AYDILLO, J. (1989): Santiago de Compostela. 1850-1950. COAG, Santiago.

CUELLO CALÓN, E. (1945): «Lo que Howard vió en España. Las cárceles y prisiones de España a fines del siglo XVIII» en R.E.P., $\mathrm{N}^{\circ} 5$ (12 a 17).

ESTRADA GALLARDO, F. (1970): «Las casas de Gómez Pérez das Mariñas y el palacio de Capitanía General» en Boletín de la Real Academia Gallega, № 352, Tomo XXX (333 a 355).

FERNÁNDEZ FERNÁNDEZ, X. (1995): Arquitectura del eclecticismo en Galicia (1874-1915). Xunta de Galicia-Universidad de La Coruña.

FORTES BOUZÁN, X. (1993): Historia de la ciudad de Pontevedra. Biblioteca Gallega, La Coruña.

"CUADERNOS DE ESTUdIOS GALLEGOS", Tomo XLVI, Fascículo 111, Santiago 1999. 
FRAILE, P. (1987): Un espacio para castigar. La cárcel y la ciencia penitenciaria en España (siglos XVIII-XIX). Ediciones del Serbal, Barcelona.

GALLEGO DOMÍNGUEZ, O. (1995): «Las Cárceles de la Provincia de Orense del Antiguo Régimen» en Aspectos Históricos de Ourense (Anexo VIII Xornadas de Historia de Galicia). Diputación Provincial de Ourense (171 a 196).

GARCÍA BASALO, J.C. (1957a y b): «Introducción a la arquitectura penitenciaria, I y II» en R.E.P., №s 126 y 130 (71 a 83 y 771 a 778).

GARCÍA BASALO, J.C. (1957c): «Introducción a la Arquitectura Penitenciaria. Evolución histórica. El Panóptico de Bentham» en R.E.P., $\mathrm{N}^{\mathrm{o}} 129,(589$ a 594$)$.

GARCÍA IGLESIAS, J.M. (1995): El Barroco (II). Proyecto Galicia. Arte. Tomo XIV. Hércules de Ediciones, A Coruña.

GARCÍA MELERO, J.E. (1995): «Las cárceles españolas de la Ilustración y su censura en la Academia (1777-1808)» en Espacio, Tiempo y Forma, Serie VII, $\mathrm{H}^{\mathrm{a}}$ del Arte, t. 8 (241 a 272).

GARCÍA-ALCAÑIZ YUSTE, J. (1989): Arquitectura del Neoclásico en Galicia. Fundación Pedro Barrié de la Maza, La Coruña.

GARRIDO RODRÍGUEZ, J. (1991): Vigo. La ciudad que se perdió. Arquitectura desaparecida. Arquitectura no realizada. Diputación Provincial de Pontevedra.

JUEGA PUIG, J. (1985): «La cárcel vieja de Pontevedra» en El Museo de Pontevedra, Tomo XXXIX (231 a 254).

JUEGA PUIG, J., PEÑA SANTOS, A. de la, y SOTELO RESURRECCIÓN, E. (1995): Pontevedra, villa amurallada. Diputación Provincial de Pontevedra.

"CUADERNOS DE eSTUdiOS GALLEGOS", Tomo XLVI, Fascículo 111, Santiago 1999. 
LANZA ÁlVAREZ, F. (1973): Ribadeo antiguo. Noticias y documentos. Ediciones del Castro, La Coruña.

LÓPEZ VÁZQUEZ, J.M. (1995): «El arte en los dos últimos tercios del siglo XIX» en Arte Contemporáneo. Tomo XV. Proyecto Galicia. Arte. Hércules de Ediciones, A Coruña.

MADOZ, P. (1847): Diccionario Geográfico-Estadístico-Histórico de España y sus posesiones de Ultramar. Madrid (Facs. De. Breogán, Madrid, 1986).

MEIJIDE PARDO, A. (1989): La Academia y Escuela de Bellas Artes de La Coruña. 1850-1875. Diputación Provincial de La Coruña.

MOLINA TABOADA, C. (1986): «Proyecto de una cárcel para la ciudad de Betanzos. 1865» en Programa Festas Patronais de San Roque, Betanzos.

MOSQUETE, D. (1957): «Reflexiones sobre Howard y la reforma penitenciaria» en R.E.P., $\mathrm{N}^{\mathrm{o}} 131$ (15 a 18).

MURUBE Y GALÁN, F. (1860): Tratado de las prisiones y sistemas penales de Inglaterra y Francia, con observaciones generales sobre lo que conviene saber para la reforma de las de España. Imp. de Manuel Mirás, Santiago.

NAYA PÉREZ, J. (1970): Calles y plazas coruñesas. Ayuntamiento de La Coruña.

ORTEGA ROMERO, M. S. (1966): «Noticias sobre la construcción del Ayuntamiento de Santiago de Compostela» en Cuadernos de Estudios Gallegos, № 65, Tomo XXI. (81 a 101).

ORTEGA ROMERO, M. S. (1981): «Notas históricas de arte gallego. Las cárceles de Santiago en el siglo XVIII: datos documentales» en C.E.G., Tomo XXXV (525 a 530). 
ORTEGA ROMERO, M. S. (1983): «En torno a la construcción del Palacio de Rajoy en Santiago de Compostela» en E.M.P., Tomo XXXVII (325 a 330).

ORTEGA ROMERO, M.S. (1987): «Un proyecto de Fernando de Casas para el Tribunal de la Inquisición de Santiago» en Jubilatio. Homenaje de la Facultad de Geografía e Historia a los profesores D. Manuel Lucas Alvarez y D. Angel Rodríguez González (VV.AA.). Universidad de Santiago.Vol. II (653 a 668).

OTERO TÚÑEZ, R. (1969): «Melchor de Prado y la Academia de San Fernando»en C.E.G., N ${ }^{\text {os }}$ 72-73-74, Tomo XXIV (126 a 139).

PÉREZ RODRÍGUEZ, F. (1995): «Un escenario privilegiado para las fiestas del Apóstol Santiago: la plaza del Obradoiro» en C.E.G., N ${ }^{\circ} 107$, Tomo XLII (239 a 272).

PEVSNER, N. (1979): «Prisiones» en Historia de las tipologías arquitectónicas. Gustavo Gili, Barcelona.

RISCO, V. (1930): «Provincia de Orense», Vol. XI, en G.G.R.G. (CARRERAS CANDI, F.). Ed. Alberto Martín, Barcelona.

SÁNCHEZ GARCÍA, J. A. (1995): «Del neoclasicismo al eclecticismo en la arquitectura gallega. Tres hitos en la obra de Faustino Domínguez Domínguez (1817-1890)» en C.E.G., No 107 (313 a 337).

SORALUCE BLOND, J. R. (1985): Castillos y fortificaciones de Galicia. La arquitectura militar de los siglos XVI-XVIII. Fundación Pedro Barrié de la Maza, La Coruña.

VIGO TRASANCOS, A. (1984): Arquitectura y urbanismo en el Ferrol del siglo XVIII. COAG, Santiago.

VIGO TRASANCOS, A. (1990): «A arquitectura da Ilustración e do século XIX» en A arte galega. Estado da cuestión. Consello da Cultura Galega, La Coruña.

"CUADERNOS DE ESTUdIOS GALLEGOS", Tomo XLVI, Fascículo 111, Santiago 1999. 
VIGO TRASANCOS, A. (1992): «La intervención del Estado dieciochesco en la arquitectura gallega de iniciativa privada: el papel de los ingenieros y la obra de Carlos Lemaur» en C.E.G., $\mathrm{N}^{\circ} 105$, (103 a 133).

VIGO TRASANCOS, A. (1995a): La arquitectura de la Ilustración. Clasicismo y Neoclasicismo (1700-1834). Biblioteca Coruñesa. Vía Láctea ed.-Ayuntamiento de La Coruña.

VIGO TRASANCOS, A. (1995b): «El arquitecto benedictino Fray Plácido Caamiña y su proyecto de casas consistoriales y cárceles para la ciudad de Ferrol (1791)» en C.E.G., N 107, Tomo XLII (273 a 312). 